\title{
Striatal Cholinergic Interneurons Are a Novel Target of Corticotropin Releasing Factor
}

\author{
이 Julia C. Lemos, ${ }^{1,4}$ ○Jung Hoon Shin, ${ }^{1}$ and $\odot$ Veronica A. Alvarez ${ }^{1,2,3}$ \\ ${ }^{1}$ National Institute on Alcohol Abuse and Alcoholism, ${ }^{2}$ National Institute on Drug Abuse, ${ }^{3}$ Center on Compulsive Behaviors, Intramural Research Program, \\ NIH, Bethesda, Maryland 20892, and ${ }^{4}$ Department of Neuroscience, University of Minnesota, Minneapolis, Minnesota 55455
}

Cholinergic interneurons (CINs) are critical regulators of striatal network activity and output. Changes in CIN activity are thought to encode salient changes in the environment and stimulus-response-outcome associations. Here we report that the stress-associated neuropeptide corticotropin releasing factor (CRF) produces a profound and reliable increase in the spontaneous firing of CINs in both dorsal striatum and nucleus accumbens (NAc) through activation of CRF type 1 receptors, production of cAMP and reduction in spike accommodation in male mice. The increase of CIN firing by CRF results in the activation muscarinic acetylcholine receptors type 5, which mediate potentiation of dopamine transmission in the striatum. This study provides critical mechanistic insight into how CRF modulates striatal activity and dopamine transmission in the NAc to likely account for CRF facilitation of appetitive behaviors.

Key words: acetylcholine; dopamine transmission; muscarinic receptors; nucleus accumbens; striatum

\section{Significance Statement}

Although the presence of CRF receptors in the dorsal and ventral striatum has been acknowledged, the cellular identity and the functional consequences of receptor activation is unknown. Here we report that striatal cholinergic interneurons express CRF-R1 receptors and are acutely activated by the neuropeptide CRF that is released in response to salient environmental stimuli. Cholinergic interneurons make $<1 \%$ of the cells in the striatum but are critical regulators of the striatal circuitry and its output. CRF's fast and potent activation of cholinergic interneurons could have far reaching behavioral implications across motivated behaviors controlled by the striatum.

\section{Introduction}

Cholinergic interneurons (CINs) are critical regulators of striatal activity despite constituting a small percentage (1-2\%) of somata within the striatum. This is because of their highly ramified morphology that enables a single neuron to release acetylcholine across a large volume (Tanimura et al., 2018). As such, this population constitutes one of the largest sources of acetylcholine in the brain and is the primary source of acetylcholine to the main output neurons of the striatum, medium spiny projection neurons (MSNs; Tanimura et al., 2018). Activation of ionotropic and metabotropic acetylcholine receptors within the striatum pro-

\footnotetext{
Received March 1, 2019; revised May 3, 2019; accepted May 11, 2019.

Author contributions: J.C.L. and V.A.A. designed research; J.C.L. performed research; J.H.S. contributed unpublished reagents/analytic tools; J.C.L. analyzed data; J.C.L., J.H.S., and V.A.A. wrote the paper.

This work was supported by Intramural Programs of NIAAA, NINDS (ZIA-AA000421) to V.A.A., K99/R00 Pathway to Independence award (MH109627) to J.C.L., and 2017 Innovation Award from NIH-DDIR to V.A.A. We thank Dr. Jurgen Wess for the M5KO mice, Dr. Steven Vogel for access to the confocal microscope, and Dr. David Lovinger and other members of the Alvarez laboratory for helpful comments and discussion.

The authors declare no competing financial interests.

Correspondence should be addressed to Julia C. Lemos at jlemos@umn.edu or Veronica A. Alvarez at alvarezva@mail.nih.gov.

https://doi.org/10.1523/JNEUROSCI.0479-19.2019

Copyright $\odot 2019$ the authors
}

duces changes in glutamatergic synaptic strength on MSNs, changes in MSN excitability and ultimately striatal output (Goldberg et al., 2012; Abudukeyoumu et al., 2019). Behaviorally, CINs have a diverse set of roles within reward learning and motivation depending on the specific striatal subregion and behavioral context. For example, CIN ablation as well as pharmacological manipulations of acetylcholine transmission within the dorsomedial striatum suggest that CINs are critical in signaling changes in reward contingencies that enable behavioral flexibility (Ragozzino, 2003, 2009; Okada et al., 2018). The role of CINs in the nucleus accumbens (NAc) is more controversial. Recently, a study showed that silencing of CINs within the NAc produced anhedonic-like states (measured as a reduction in sucrose preference) as well as a bias toward "passive" versus "active" coping strategies (Warner-Schmidt et al., 2012). It was also recently suggested that insulin potentiation of CIN activity in the NAc was necessary for acquiring preference for one reward type over another (Stouffer et al., 2015). These data suggest that CINs in the NAc are critical for promoting engagement in appetitive behaviors and are actively responding to environmental challenges.

Corticotropin releasing factor (CRF) is a neuropeptide neuromodulator that is often released in response to salient environ- 
mental stimuli including acute stressors (Cook, 2004; Merali et al., 2004; Wang et al., 2005; Ohmura et al., 2009; Holly et al., 2016). CRF has canonically been defined as the initiation factor of the hypothalamic-pituitary-adrenal axis response (Bale and Vale, 2004; Bale, 2006). However, both CRF and its two receptors, CRF type 1 receptors (CRF-R1) and CRF type 2 receptors (CRF-R2) are widely distributed throughout the brain, beyond the hypothalamic area (Steckler and Holsboer, 1999; Van Pett et al., 2000; Justice et al., 2008; Kühne et al., 2012; Henckens et al., 2016). Recently, it was shown that salient environmental stimuli, such as a novel object, trigger CRF release in the NAc (Lemos et al., 2012). Recent evidence suggests that CRF acting in the NAc can promote appetitive/approach behaviors including cue-triggered operant behaviors, novelty exploration, and social affiliation behavior (Peciña et al., 2006; Lim et al., 2007; Lemos et al., 2012). This behavioral effect of CRF has been linked to the observation ex vivo that CRF can potentiate striatal DA transmission in brain slices. These and in vivo microdialysis experiments, also support the concept that CRF acts on dopamine axon terminals in the NAc to potentiate DA transmission, an effect independent of CRF actions at DA neuron soma (Chen et al., 2012; Lemos et al., 2012). However, the cellular and circuit mechanisms underlying this CRF effect in the striatum remain unclear.

Infusion of CRF into the NAc increases local levels of acetylcholine, in addition to DA, as shown by microdialysis experiments (Chen et al., 2012). Acetylcholine can both trigger and modulate dopamine release through activation of nicotinic and muscarinic acetylcholine receptors, respectively, which are thought to be localized to dopamine axonal projections. Work from Dani laboratory demonstrated that electrically evoked dopamine transients in ex vivo slices are highly sensitive to antagonism of $\beta 2$-containing nicotinic AChR (nAChRs; Zhou et al., 2002; Zhang et al., 2004). Direct optogenetic stimulation of CINs within the dorsal or ventral striatum can evoke DA transients, and this signal is completely dependent on activation of nAChRs (Cachope et al., 2012; Threlfell et al., 2012; Shin et al., 2017). The kinetics of these DA signals, along with electron microscopy data, support a working model where $\beta 2$-containing nAChRs localized along DA axons and terminals can locally depolarize these compartments and evoke DA release in response to acetylcholine release independently of the firing of action potentials at DA neuron soma (Wonnacott et al., 2000). Further, activation of muscarinic acetylcholine receptors can also modulate DA transmission. On one hand, Gi/o-coupled muscarinic receptor type 2 (M2) and muscarinic receptor type 4 (M4) M2 and M4 receptors, which are expressed on striatal CINs and act as autoreceptors, suppress acetylcholine transmission and, in turn, dopamine transmission in the striatum (Yan and Surmeier, 1996; Threlfell et al., 2012; Shin et al., 2015). On the other, Gq-coupled muscarinic receptor type 5 (M5) M5 receptors localized to dopamine processes potentiates dopamine transmission (Zhang et al., 2002; Schmidt et al., 2010; Shin et al., 2015).

Based on these facts, we reasoned that CRF could enhance DA transmission by activating striatal CINs. In support this hypothesis, an independent study demonstrated that stress-evoked dopamine transmission in the NAc was reduced by selective ablation of CINs in NAc (Laplante et al., 2013). Thus, we sought to test the hypothesis directly by measuring the acute effect of exogenously applied CRF on CIN activity within the dorsal striatum (DS) and NAc. Moreover, we tested whether the CRFmediated potentiation of DA transmission in the NAc required nAChRs and/or mAChR activation. We found that indeed CINs express CRF-R1 receptors and that acute application of CRF in- creases the spontaneous firing of these neurons. Blocking muscarinic AChRs, but not nAChRs, reduced the CRF-induced potentiation of DA transmission and M5 knock-out mice also showed impaired CRF-potentiation of DA signals.

\section{Materials and Methods}

All procedures were performed in accordance with guidelines from the Animal Care and Use Committee of the National Institute on Alcohol Abuse and Alcoholism or University of Minnesota.

Animals. Male mice (P60-P180) were group housed and kept under a $12 \mathrm{~h}$ light cycle (06:30 ON/18:30 OFF) with food and water available ad libitum. Based on the literature, it is highly likely that there are sex differences in CRF regulation of striatal circuitry (Valentino et al., 2013). Thus, in this study we focused on male mice and are conducting an independent thorough investigation of the CRF regulation of CINs in female mice across estrous cycle. For ex vivo electrophysiology experiments ChAT-ires-Cre ${ }^{+/-}$(Jax stock: 018957) x Ai14;tdTomato Reporter (B6.CgGt(ROSA)26Sortm14(CAG-tdTomato)Hze/J, (Jax stock: 007914) were used. M5KO homozygous mice backcrossed onto a C57BL/6J background were provided by Dr. Jurgen Wess and bred in the vivarium facility at NIAAA. Control mice were C57BL/6J mice obtained from Jackson Laboratories and bred concurrently in the vivarium facility at NIAAA. C57Bl6J control mice and M5KO mice were age matched.

Immunohistochemistry. CIN reporter mice were intracardially perfused with PBS containing $10 \mathrm{U} / \mathrm{ml}$ heparin until the liver cleared $(\sim 5$ $\mathrm{min}$ ) followed by $40 \mathrm{ml}$ fixative solution (4\% paraformaldehyde; $4 \%$ sucrose in $0.1 \mathrm{M} \mathrm{PB}$ ) at $3 \mathrm{ml} / \mathrm{min}$. Brain was removed, postfixed overnight and then kept in $30 \%$ sucrose in $0.1 \mathrm{M} \mathrm{PB}$. Coronal or sagittal floating sections $(40 \mu \mathrm{m})$ were prepared using cryostat (Leica CM3050). Floating sections were washed in PBS and then blocked for $1 \mathrm{~h}$ in $5 \%$ donkey serum, $0.3 \%$ Triton-X in PBS at room temperature (RT). Sections were then incubated in primary antibody (goat anti-ChAT, 1:1000; AB144P) for $12-18 \mathrm{~h}$ at RT. Following $3 \times 10$ min washes in PBS, sections were incubated in donkey secondary antibodies conjugated with AlexaFluor (1:500; Invitrogen) for $2 \mathrm{~h}$ at RT. Slices were washed $3 \times 10 \mathrm{~min}$ in PBS, then $2 \times 10 \mathrm{~min}$ in $0.1 \mathrm{M}$ PB. Images $(512 \times 512$ or $1024 \times 1024)$ were acquired using a confocal microscope (Zeiss LSM 510 META) and analyzed using Image $(\mathrm{NIH})$.

Fluorescent ISH using RNAscope (R) - registered trademark. Brains were rapidly dissected and flash frozen in isopentane on dry ice. Brains were kept in a $-80^{\circ} \mathrm{C}$ freezer until they were sectioned. Coronal or sagittal brain slices $(16 \mu \mathrm{m})$ containing the DS and NAc were thaw mounted onto Superfrost plus slides (Electron Microscopy Sciences) using a Leica CM 1900 cryostat maintained at $-20^{\circ} \mathrm{C}$. Note, before section, brains were equilibrated in the cryostat for at least $2 \mathrm{~h}$. Slides were cleaned with RNAzap, to prevent mRNA degradation. Slides were stored at $-80^{\circ} \mathrm{C}$. RNAscope (R) - registered trademark in situ hybridization (ISH) was conducted according to the Advanced Cell Diagnostics user manual and as previously reported (Tejeda et al., 2017). Briefly, slides were fixed in $10 \%$ neutral buffered formalin for $20 \mathrm{~min}$ at $4^{\circ} \mathrm{C}$. Slides were washed $2 \times$ 1 min with $1 \times$ PBS, before dehydration with $50 \%$ ethanol $(1 \times 5 \mathrm{~min})$, $70 \%$ ethanol $(1 \times 5 \mathrm{~min})$, and $100 \%$ ethanol $(2 \times 5 \mathrm{~min})$. Slides were incubated in $100 \%$ ethanol at $-20^{\circ} \mathrm{C}$ overnight. The following day, slides were dried at RT for $10 \mathrm{~min}$. A hydrophobic barrier was drawn around the sections using a hydrophobic pen and allowed to dry for $15 \mathrm{~min}$ at RT. Sections were then incubated with Protease Pretreat- 4 solution for 20 $\mathrm{min}$ at RT. Slides were washed with $\mathrm{ddH}_{2} \mathrm{O}(2 \times 1 \mathrm{~min})$, before being incubated with the appropriate probes for $2 \mathrm{~h}$ at $40^{\circ} \mathrm{C}$ in the $\mathrm{HybEZ}$ oven [Advanced Cell Diagnostics (ACD)]. The following probes were purchased from ACD: Mm-Crh1-C1 (catalog \#418011), Mm-Crh2-C1 (catalog \#413201), Mm-Crh-C1 (catalog \#316091), and Mm-Chat-C2 (catalog \#408731-C2). Following incubation with the appropriate probes, slides were subjected to a series of amplification steps at $40^{\circ} \mathrm{C}$ in the HybEZ oven with $2 \times 2$ min washes (w/agitation) in between each amplification step at RT. Amplification steps were as followed: Amp 1 at $40^{\circ} \mathrm{C}$ for $30 \mathrm{~min}, \mathrm{Amp} 2$ at $40^{\circ} \mathrm{C}$ for $15 \mathrm{~min}, \mathrm{Amp} 3$ at $40^{\circ} \mathrm{C}$ for $30 \mathrm{~min}$, and Amp 4-Alt A at $40^{\circ} \mathrm{C}$ for $15 \mathrm{~min}$. A DAPI-containing solution was applied to sections (one slide at a time) at RT for 20 s. Finally, slides were 
coverslipped using ProLong Gold Antifade mounting media and stored at $4^{\circ} \mathrm{C}$ until imaging on a confocal microscope (Zeiss).

Image analysis and quantification for RNAscope. Sections were imaged using a Zeiss confocal microscope and Zen software. Unique $20 \times(5 \mu \mathrm{m}$ thick) and $40 \times$ images ( $2 \mu \mathrm{m}$ thick) were acquired from DS and NAc mice using the same software and hardware settings. The settings were titrated for each specific experimental probe. Quantification was done using Fiji/ImageJ software. Numbers of DAPI cells were automatically generated using the particle counter function in ImageJ. Numbers of choline acetyltransferase (ChAT) cells and ChAT+/CRF-R1, +R2, or + CRF-positive cells were manually counted using the cell counter function. For both ChAT and DAPI cells, cells were considered positive for the experimental probe, if there $>5$ particles clustered around (but not in) the cell nucleus. The thresholding was kept consistent across images.

In vitro electrophysiology. Coronal slices $(240 \mu \mathrm{m})$ containing the DS and NAc core were prepared from 8- to 16-week-old mice ChAT-ires$\mathrm{CRE}^{+/-}$;Ai14 tdTomato mice. Slices were cut in ice-cold cutting solution containing the following (in mM): 225 sucrose, $13.9 \mathrm{NaCl}, 26.2 \mathrm{NaHCO}_{3}$, $1 \mathrm{NaH}_{2} \mathrm{PO}_{4}, 1.25$ glucose, $2.5 \mathrm{KCl}, 0.1 \mathrm{CaCl}_{2}, 4.9 \mathrm{MgCl}_{2}$, and 3 kynurenic acid. Slices were maintained in oxygenated ACSF containing the following (in mM): $124 \mathrm{NaCl}, 2.5 \mathrm{KCl}, 2.5 \mathrm{CaCl}_{2}, 1.3 \mathrm{MgCl}_{2}, 26.2 \mathrm{NaHCO}_{3}, 1$ $\mathrm{NaH}_{2} \mathrm{PO}_{4}$, and 20 glucose $(\sim 310-315 \mathrm{mOsm})$ at RT following a $1 \mathrm{~h}$ recovery period at $33^{\circ} \mathrm{C}$. Cell-attached recordings in voltage-clamp mode were performed to measure the effect of CRF on CIN firing frequency. For cell-attached recordings, electrodes were filled with filtered ACSF (the same that was used for external solution). A gigaohm seal was achieved, maintained, and monitored. Cells in which the gigaohm seal had degraded were excluded. Current-clamp recordings were performed using electrodes (resistance 2.5-4 M $\Omega$ ) filled with $120 \mathrm{KMeSO}_{4}, 20 \mathrm{KCl}$, 10 HEPES, 0.2 K-EGTA, $2 \mathrm{MgCl}_{2}$, $4 \mathrm{Na}$-ATP, and $0.4 \mathrm{Na}-\mathrm{GTP}$, pH 7.25 $(\sim 290 \mathrm{mOsm})$. Within $5 \mathrm{~min}$ after achieving whole-cell configuration, CINs often became hyperpolarized and eventually stopped firing. Thus, current steps ( $800 \mathrm{~ms}$ duration) were applied from a held resting potential $(-70 \mathrm{mV})$ to investigate the effect of CRF on firing. Data were acquired at $5 \mathrm{kHz}$ and filtered at $1 \mathrm{kHz}$ using MultiClamp 700B (Molecular Devices). Data were analyzed using pClamp (Clampfit v10.3).

Fast scanning cyclic voltammetry. Brain slices from C57BL/6J or M5KO were prepared as described in the electrophysiology section using the same external solution and cutting solution. Carbon fiber $(7 \mu \mathrm{m}$ diameter, Goodfellow) electrodes were fabricated with glass capillary (602000, A-M Systems) using a Sutter P-97 puller and fiber tips were hand cut to $100-150 \mu \mathrm{m}$ past the capillary tip. Immediately before the experiments, they were filled with $3 \mathrm{M} \mathrm{KCl}$ internal solution. The carbon-fiber electrode was held at $-0.4 \mathrm{~V}$ and a voltage ramp to and from $1.2 \mathrm{~V}(400 \mathrm{~V} / \mathrm{s})$ was delivered every $100 \mathrm{~ms}(10 \mathrm{~Hz})$. Before recording, electrodes were conditioned by running the ramp at $60 \mathrm{~Hz}$ for $15 \mathrm{~min}$ and at $10 \mathrm{~Hz}$ for another $15 \mathrm{~min}$ and calibrated. Electrodes were calibrated using $1 \mu \mathrm{M}$ DA. DA transients were evoked by electrical stimulation delivered through a glass microelectrode filled with ACSF. Either a single monophasic pulse $(0.2 \mathrm{~ms}, 300 \mu \mathrm{A})$ or trains of pulses ( 5 pulses at $5,10,25,100$ $\mathrm{Hz}$ ) was delivered to the slice in the absence or presence of the nAChR antagonist $\mathrm{Dh} \beta \mathrm{E}(1 \mu \mathrm{M})$. Data were acquired with a retrofitted headstage and Axon Amplifier using MultiClamp. Voltammetric analysis was done using custom written procedures in IgorPro software. The voltammogram, peak amplitude, and area of the DA transient were measured. Experiments were rejected when the evoked current did not have the characteristic electrochemical signature of DA assessed by a currentvoltage plot.

Pharmacology. Table 1 lists the pharmacological antagonists and blockers used in this study including final concentration, route of application, what it was dissolved in, and source of the agent.

Statistics and calculations. Statistical analysis was performed in Prism (GraphPad) and Excel. Unless stated, two-tailed unpaired $t$ test was used. Otherwise, two-tailed paired $t$ test, one-way ANOVAs or two-way repeated-measures (RM) ANOVAs or one-tailed $t$ tests were used when appropriate and stated. Two-way ANOVAs were followed up with a Dunnett's or Sidak-corrected $t$ test comparisons. All data are presented as mean \pm SEM. For cell-attached experiments, frequency measurements were obtained every $30 \mathrm{~s}$ and the means were calculated for the last $3 \mathrm{~min}$
Table 1. List of pharmacological agents used, their properties and sources

\begin{tabular}{|c|c|c|c|c|c|}
\hline Agent name & Target & Final [] & Route & Dissolved in? & Source \\
\hline NBI 35695 & CRF-R1 & $1 \mu \mathrm{M}$ & Bath $^{a}$ & Water & Tocris Bioscience \\
\hline Astressin 2B & CRF-R2 & $300 \mathrm{~nm}$ & Bath $^{a}$ & Water & Tocris Bioscience \\
\hline CP $154,5626^{b}$ & CRF-R1 & $1 \mu \mathrm{M}$ & Bath $^{a}$ & $\mathrm{DMSO}^{e}$ & Tocris Bioscience \\
\hline NBQX' & AMPA & $20 \mu \mathrm{M}$ & Bath & $\mathrm{DMSO}^{e}$ & HelloBio \\
\hline Gabazine $^{c}$ & GABA-A & $5 \mu \mathrm{M}$ & Bath & Water & HelloBio \\
\hline$C P P^{c}$ & NMDA & $5 \mu \mathrm{M}$ & Bath & Water & AbCam \\
\hline CGP $55845^{\circ}$ & GABA-B & $2 \mu \mathrm{M}$ & Bath & Water & AbCam \\
\hline ZD 7288 & $\mathrm{HCN}$ & $1 \mu \mathrm{M}$ & Bath $^{d}$ & Water & Tocris Bioscience \\
\hline Apamin & SK channels & $300 \mathrm{~nm}$ & Bath & Water & Tocris Bioscience \\
\hline Rp-cAMPs & CAMP & $100 \mu \mathrm{M}$ & Internal & Water & Sigma-Aldrich \\
\hline PKI 14-22 & PKA & $1 \mu \mathrm{M}$ & Bath $^{d}$ & Water & Tocris Bioscience \\
\hline GÖ 6983 & PKC & $3 \mu \mathrm{M}$ & Bath & $\mathrm{DMSO}^{e}$ & Tocris Bioscience \\
\hline Chelrythrine & PKC & $3 \mu \mathrm{M}$ & Internal & Water & Tocris Bioscience \\
\hline $\mathrm{DH} \beta \mathrm{E}$ & nAChR & $1 \mu \mathrm{M}$ & Bath & DMSO $^{e}$ & Tocris Bioscience \\
\hline Scopolamine & $\mathrm{mAChR}$ & $1 \mu \mathrm{M}$ & Bath & Water & Tocris Bioscience \\
\hline
\end{tabular}

${ }^{a}$ Twenty minute pre-incubation prior to start of the experiment.

${ }^{b}$ In text, not displayed in figure.

'Co-applied.

${ }^{d}$ Ten minute pre-incubation prior to the start of the experiment.

${ }^{e}$ Final [] of DMSO in bath was $0.0001 \%$.

of recording in baseline or CRF application. For voltammetry experiments, transients were evoked every $2 \mathrm{~min}$ and means were calculated for the last 6 min of drug application or baseline. In all experiments, CRF produced a stable maximal effect by $15-20 \mathrm{~min}$ of bath application. Results were considered significant at an $\alpha$ of 0.05 .

\section{Results}

\section{CRF enhances CIN firing in DS and NAc}

CINs make up only 1-2\% of neurons within DS and NAc, which makes recording from these neurons in a high throughput fashion challenging. To aid with visualization of striatal CINs, recordings were performed in ChAT-ires-Cre ${ }^{+/-}$mice crossed with the Cre-dependent reporter mouse line Ail 4 tdTomato (CIN reporter; Fig. $1 a$ ). In the DS and NAc core, $>80 \%$ of red fluorescentlylabeled Cre + cells showed immunoreactivity for ChAT (Fig. 1b; dorsomedial striatum (DMS), DMS: $85 \pm 4 \%$, dorsolateral striatum (DLS), DLS: $82 \pm 4 \%$, NAc core: $87 \pm 5 \%, n=16-18$ unique images from 3 to 4 mice). The NAc shell showed only $74 \pm 4 \%$ coexpression; thus, we avoided the NAc shell for our recordings. Notably, the NAc core had significantly fewer CRE+/ ChAT-ir + somata compared with the other striatal subregions (one-way ANOVA, $F_{(3,64)}=7.437, p=0.002, n=16-18$ unique images from 3 to 4 mice; Fig. 1c). In addition to ChAT immunoreactivity, we confirmed that $\mathrm{CRE}+$ cells displayed the classic large somatic morphology and electrophysiological properties of CINs (i.e., spontaneously active, $I_{\mathrm{h}}$ sag and accommodation; Fig. $1 d, e)$. As seen in many other spontaneously active neurons, CINs showed a "run-down" of the spontaneous firing in whole-cell configuration, because of the dialysis of the cytoplasm by the internal solution. For this reason, the majority of electrophysiological recordings were conducted in a cell-attached configuration with gigaohm seal maintained throughout the recording.

Bath application of CRF ( $100 \mathrm{~nm}$ ) on to the brain slices significantly increased the spontaneous firing of CINs in both the NAc (core and core/shell border) and DS (dorsolateral and dorsomedial combined; NAc: $2.6 \mathrm{~Hz}$ to $6.2 \mathrm{~Hz}$; DS: $0.7 \mathrm{~Hz}$ to $2.7 \mathrm{~Hz}$, two-way RM ANOVA, main effect of drug: $F_{(1,19)}=99.83$, post hoc Sidak's $t$ tested, $p$ values $<0.0001, n=10-12$; Fig. $2 a, b$ ). When normalized to baseline firing, CRF increased CIN firing by $153 \pm 22 \%$ in NAc and $407 \pm 96 \%$ in DS (Fig. $2 c, d$ ). The maximal effect was achieved by $\sim 5 \mathrm{~min}$ of CRF application. The normal- 
ized maximal CRF effect was significantly larger in the DS than the NAc ( $t$ test, $p=$ $0.038)$. It is possible that this difference could be because of regional differences in baseline firing rate. CINs in the DS had a significantly lower frequency of spontaneous AP firing compared with CINs recorded in the NAc (two-way RM ANOVA, main effect of region: $F_{(1,19)}=$ $30.29, p<0.0001)$. Qualitatively, it appeared that cells with lower firing rates at baseline had larger CRF-mediated increases in firing. To formally assess this negative correlation, we plotted the magnitude of the CRF effect in percentage as a function of the baseline firing rate in $\mathrm{Hz}$ on a semi-log plot (Fig. 2e). This analysis yielded an $R^{2}$ value of 0.51 suggesting that the baseline firing rate accounts for $\sim 50 \%$ of the size of CRF's potentiation of CIN firing, which suggests a ceiling effect on CRF action. We then assessed the concentration dependence of the CRF effect in the NAc and screened for cells with a fixed range of baseline firing rates between 1 and $5 \mathrm{~Hz}$ (Fig. 2f). The data were fitted to a sigmoidal equation that revealed an $\mathrm{EC}_{50}$ of $8.7 \mathrm{nM}$, demonstrating the high sensitivity of this novel mechanism of CRF action in the striatum (Fig. $2 g, h$ ).

Vehicle application $(0.00001 \%$ acetic acid, time-matched to CRF time course) conducted in NAc CINs produced a $23 \pm$ $10 \%$ decrease in firing over time, likely because of run-down over time. We never saw any instance of vehicle producing an increase in firing, which we interpret as evidence that CRF increase in firing is not because of the artifactual consequence of the recording.

\section{CINs express CRF-R1 receptors}

A combination of RNAscope in situ hybridization and pharmacology was used to identify the receptor subtype responsible for the CRF-mediated increase in CIN firing. Thin brain sections $(16 \mu \mathrm{m})$ containing the DS and NAc were probed for ChAT mRNA to identify CINs and multiplexed with probes for either Crh1 (CRFR1), Crh2 (CRF-R2), or Crh (CRF) mRNA. Three to four sections from three animals (9-12 sections total) were imaged using confocal microscopy and a combination of automated and manual analysis was performed using Fiji/ImageJ software. Cells showing at least five fluorescent puncta tightly clustered around the nucleus were considered positive for CRF-R1, R2 or CRF. The analysis showed that $92 \%$ and $90 \%$ of ChAT-positive neurons contained Crh1 mRNA in the NAc and DS, respectively (Fig. $3 a, b$ ). In contrast, there was no evidence of colocalization of Crh2 with ChAT mRNA in either the NAc or DS
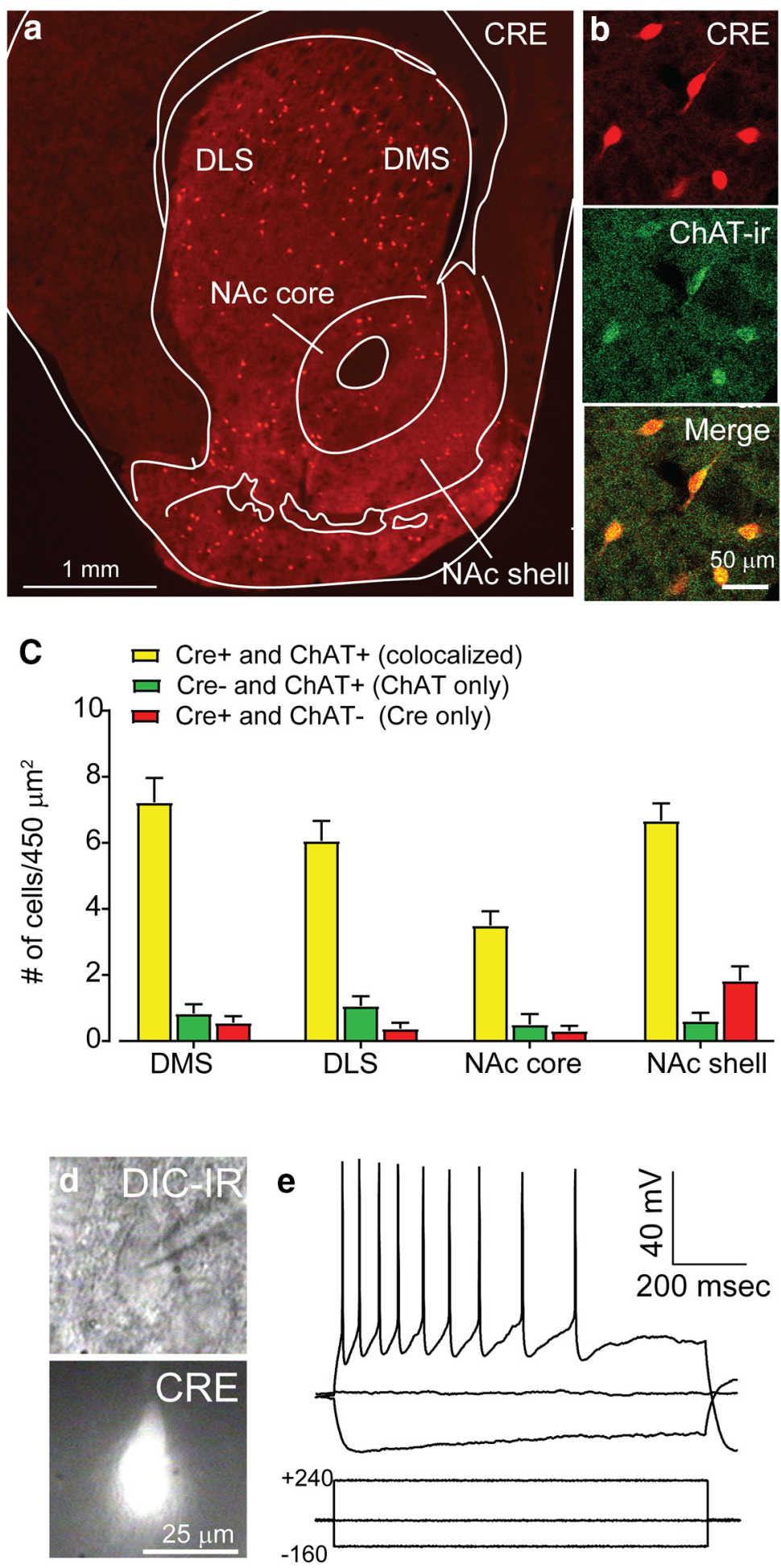

Figure 1. Validation of ChAT-IRES-CRE ${ }^{+/-}$;Ai14 reporter line. $\boldsymbol{a}, \boldsymbol{b}$, Low-power and high-power example image demonstrating CRE (tdTomato fluorescence) expression and colocalization with immunoreactivity for ChAT. c, Quantification of absolute numbers of CRE + /ChAT + cells in a $450 \mu \mathrm{m}^{2}$ area for DMS, DLS, NAc core, and NAc shell. $\boldsymbol{d}$, Example DIC-IR and fluorescent images of putative CIN labeled with tdTomato (CRE + ) recorded in a $240 \mu \mathrm{m}$ ex vivo slice preparation. $\boldsymbol{e}$, Example current-voltage trace of CRE + putative striatal CIN demonstrating typical CIN electrophysiological fingerprint.

(Fig. 3a,c). Notably, there was no evidence for colocalization of mRNAs for CRF and ChAT (data not shown), contrary to our previous report of colocalized immunostaining for CRF and ChAT (Lemos et al., 2012). As previously reported, we found a 
a Cholinergic Interneuron (CIN) - cell attached

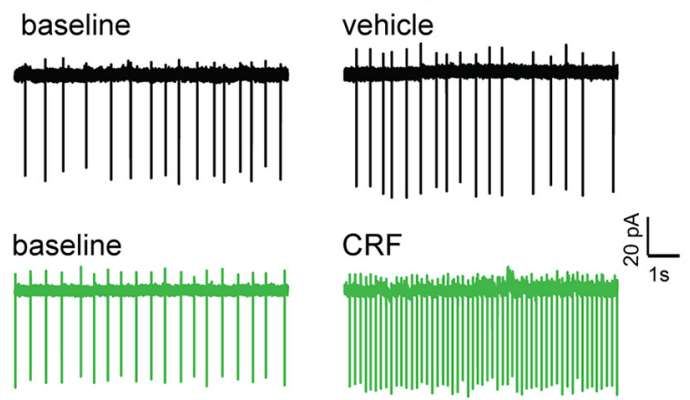

b

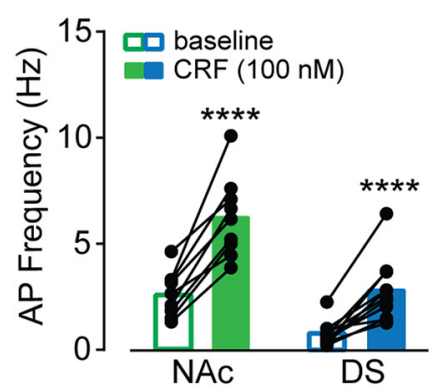

C

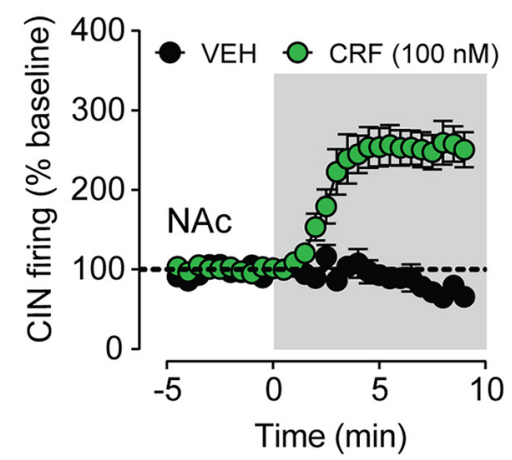

e



g

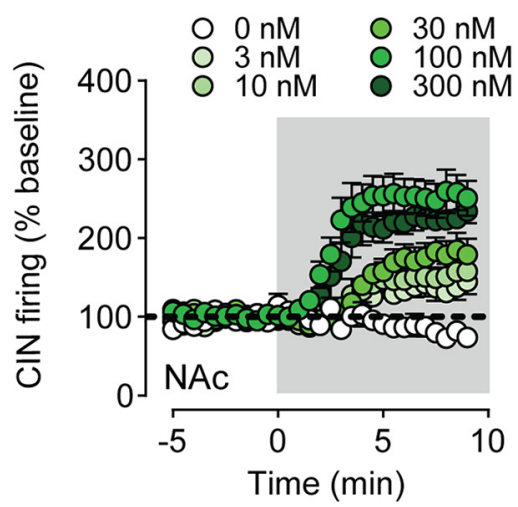

d

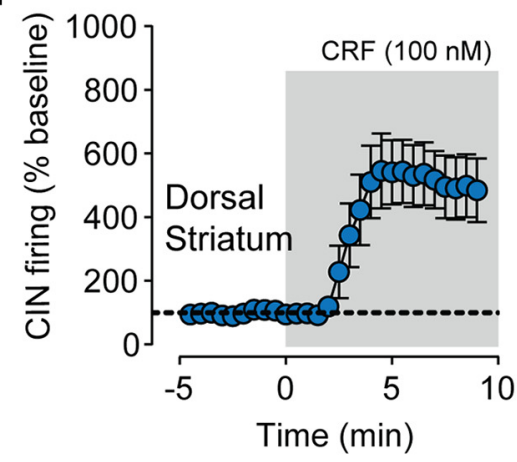

$\mathbf{f}$

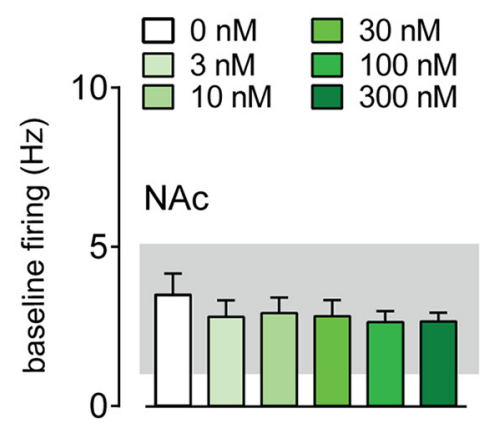

h

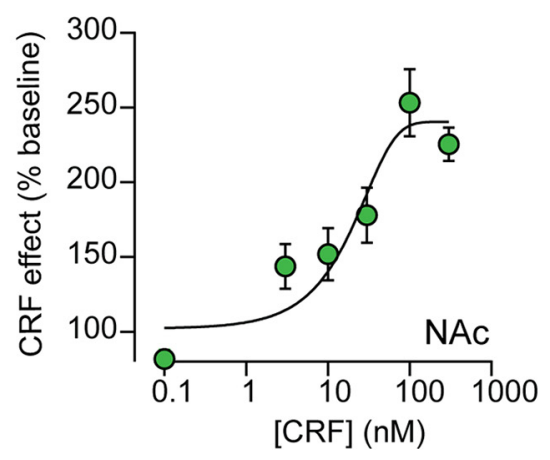

Figure 2. CRF increases the spontaneous firing of striatal cholinergic interneurons. $\boldsymbol{a}$, Example traces from CINs recorded in the NAc before and after vehicle (top) or CRF (100 nm; bottom) is bath applied. $\boldsymbol{b}$, Firing rate before and following CRF application in CINs recorded in NAc or DS. $\boldsymbol{c}, \boldsymbol{d}$, Time course of CRF/vehicle effects on CIN firing frequency normalized to the baseline, recorded in NAc (c) or DS (d).e, Semi-log plot of CRF effect (\% baseline) as a function of baseline firing frequency recorded from individual CINs in NAc (green) or DS (blue). $\boldsymbol{f}$, Average baseline firing frequencies of NAc CINs from each [CRF] $(0,3,10,30,100,300 \mathrm{~nm})$ group. $\boldsymbol{g}$, Time course of CRF effects on normalized CIN firing frequency with different [CRF] $(0,3,10,30,100,300 \mathrm{~nm})$ in the NAc. $\boldsymbol{h}$, CRF effect (\% baseline) was fit to a sigmoid curve as a function of (RF concentration. ${ }^{* * *}$, denotes statistical significance $p<0.0001$. 


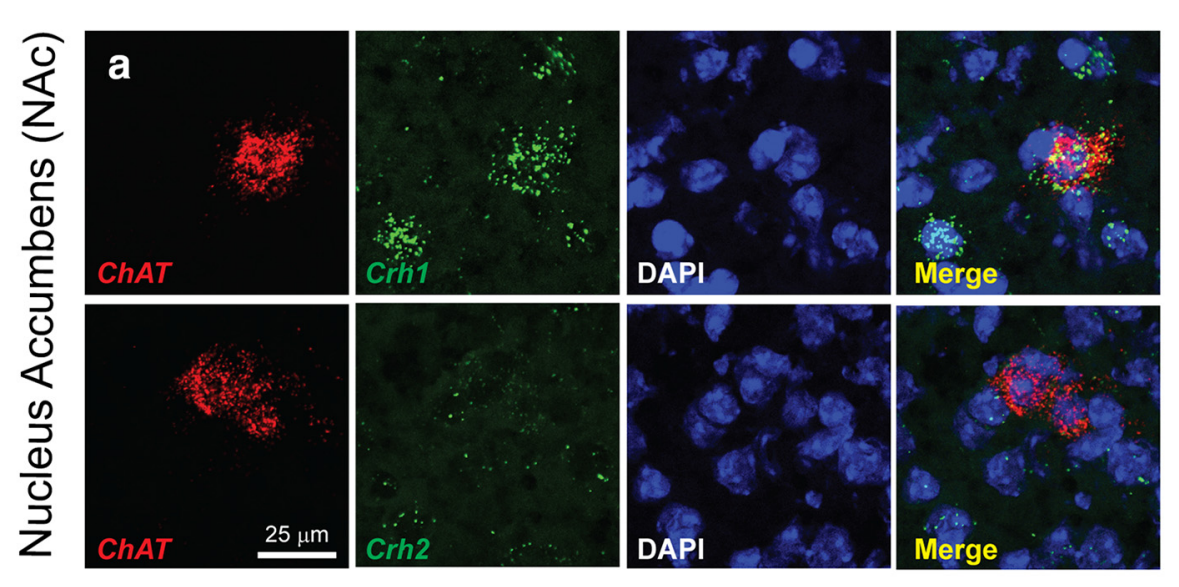

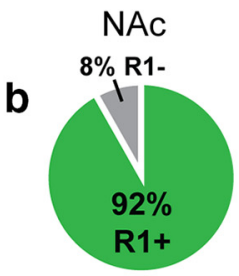

Total ChAT $+=112$

C

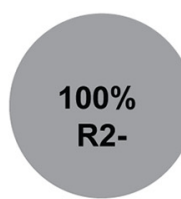

Total ChAT $+=116$
DS

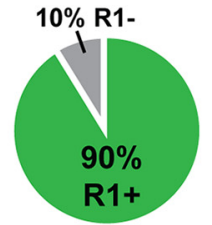

Total ChAT $+=220$

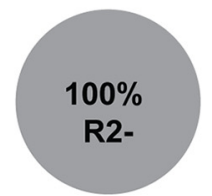

Total ChAT $+=188$
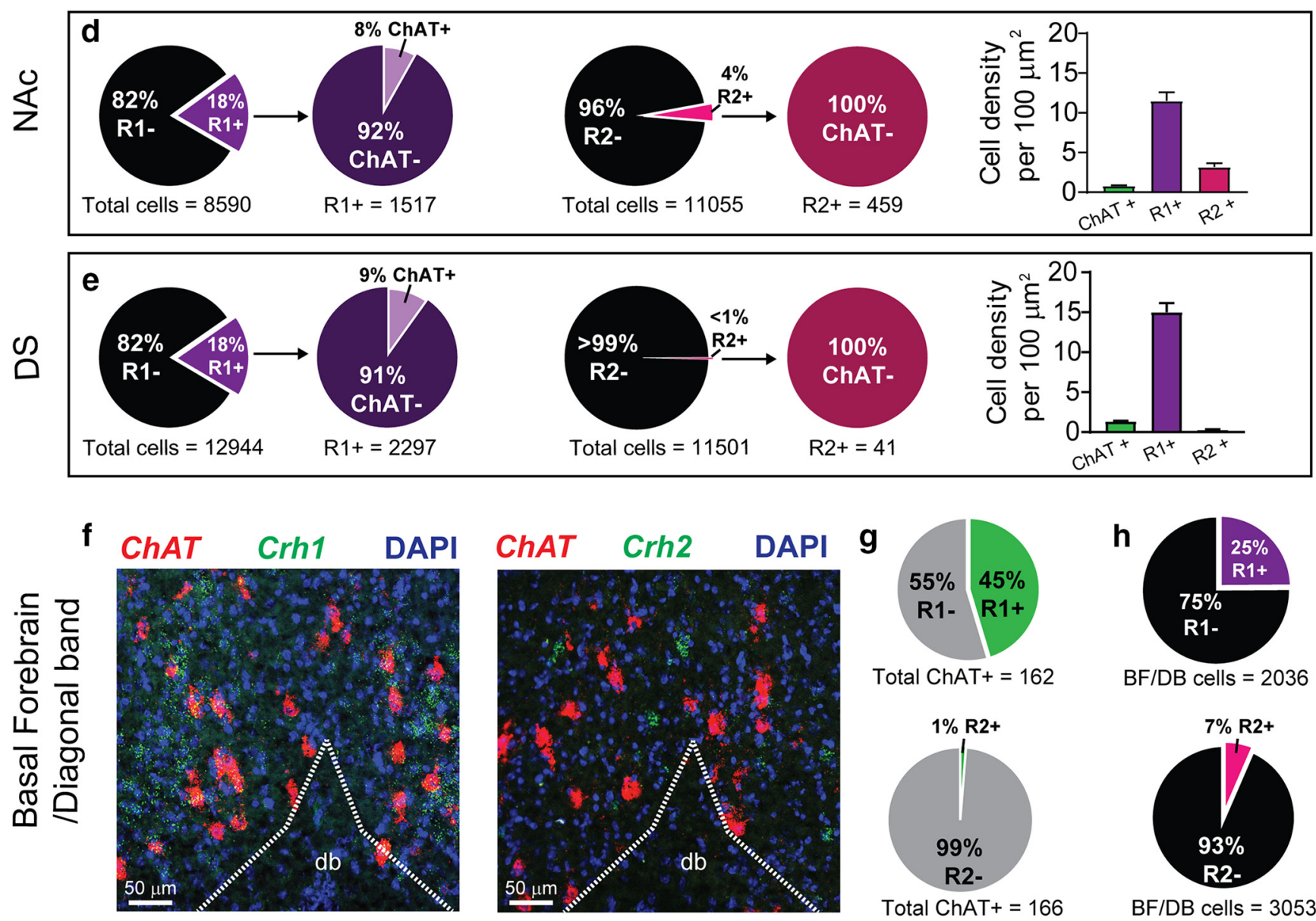

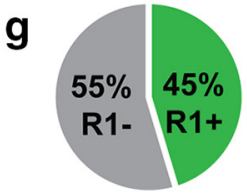

Total ChAT $+=162$



Total ChAT $+=166$

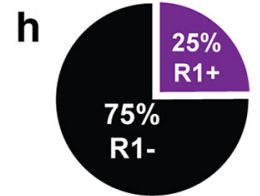

$\mathrm{BF} / \mathrm{DB}$ cells $=2036$

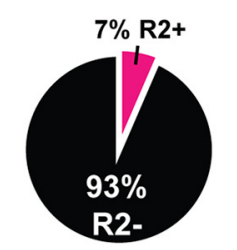

$\mathrm{BF} / \mathrm{DB}$ cells $=3053$

Figure 3. NAc and DS CINs ubiquitously express CRF-R1. a, Representative fluorescent ISH images of CIN marker ChAT mRNA (red), mRNAs (green) for Crh1 (CRF-R1, top) or Crh2 (CRF-R2, bottom) and DAPI nuclear stain (blue) in NAc. $\boldsymbol{b}$-c, Quantification of ChAT (CIN) colocalized with mRNAs for Crh1 (b), Crh2 (c), in NAc (left) or DS (right). d, Quantification of DAPI cells colocalized with mRNAs for Crh1 (left) and Crh2 (middle) in the NAc. The number of CRF-R1 +, CRF-R2+, and ChAT+ cells per $100 \mu \mathrm{m}^{2}$ (right).e, Quantification of DAPI cells colocalized with mRNAs for Crh1 (left) and Crh2 (middle) in the DS. The number of CRF-R1+, CRF-R2+, and ChAT+ cells per $100 \mu \mathrm{m}^{2}$ (right).f, Example images of ChAT and Crh1 (left) or Crh2 (right) mRNA expression in the diagonal band of the basal forebrain. $\boldsymbol{g}$, Quantification of ChAT and Crh1 (top) or Crh2 (bottom) mRNA expression in the diagonal band region of the basal forebrain using fluorescent ISH. $\boldsymbol{h}$, Quantification of DAPI and Crh1 (top) or Crh2 (bottom) mRNA expression in the diagonal band region of the basal forebrain using fluorescent ISH.

small percentage $(\sim 5 \%)$ of $C r h+$ cells in the NAc, but these were not positive for ChAT. Furthermore, there were no Crh + cells in the DS (data not shown).

We also observed Crhl mRNA expression in cells that did not express ChAT mRNA (non-cholinergic cells) within the DS and NAc. Indeed, $18 \%$ of all DAPI labeled cells were positive for CRF$\mathrm{R} 1$, and of those $18 \%$ of CRF-R1 + cells, only $8 \%$ were cholin- ergic interneurons (Fig. 3d). Negligible presence of cells expressing Crh 2 mRNA in the DS $(<1 \%)$ but, in the NAc, $4 \%$ of cells were positive for Crh2 mRNA, none of which were cholinergic interneurons (Fig. 3e). Future work will be needed to determine the identity of those cells expressing mRNA for CRF-R1 and R2, which are presumed noncholinergic neurons based on undetectable labeling for ChAT mRNA. 
a in CRF-R antagonists
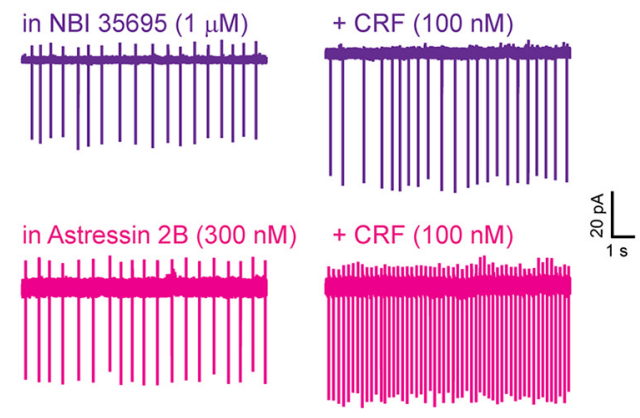

d in NBQX, GZ, CPP, CGP (GABA/GLUT)
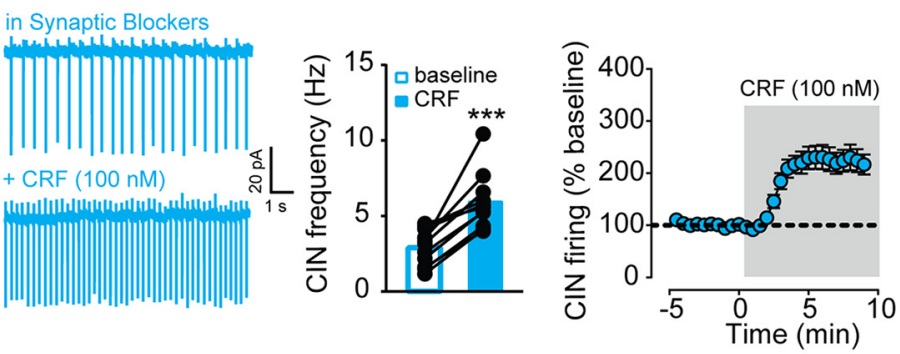

g in ZD 7288

( $\mathrm{HCN}$ channels)
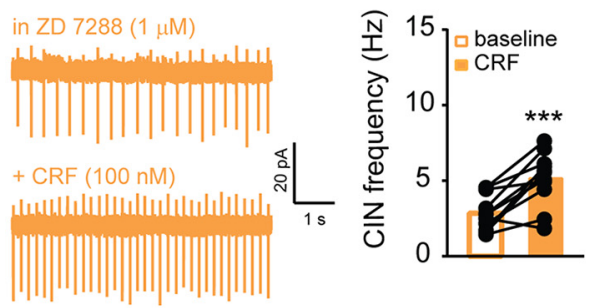

b

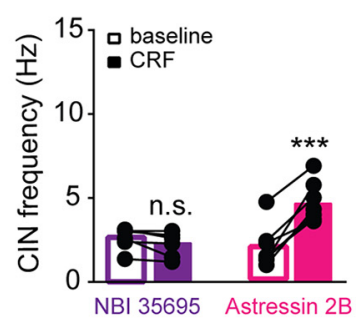

C



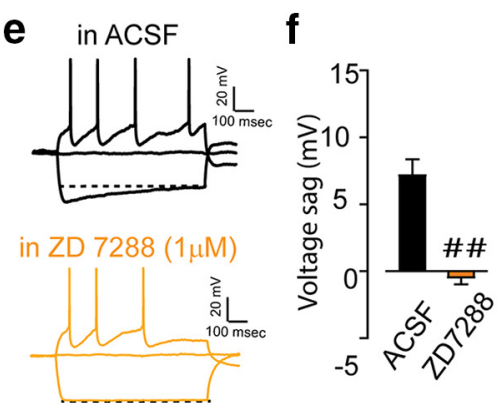

$\mathbf{h}$
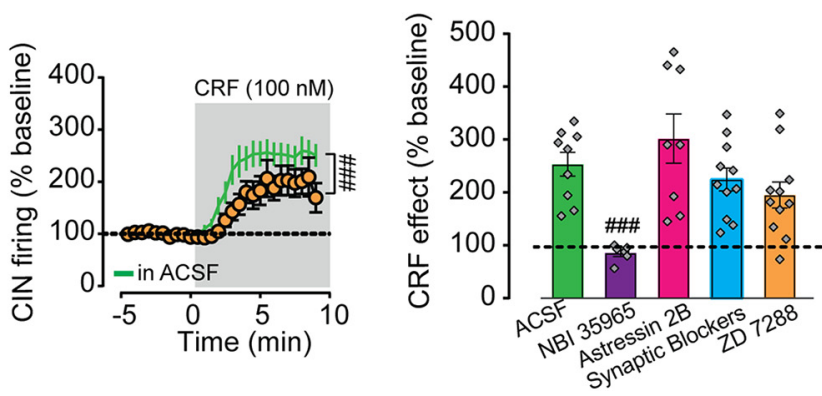

Figure 4. CRF-mediated increase in CIN firing requires CRF-R1. $\boldsymbol{a}$, Representative traces of CIN firing before and after CRF bath application in the presence of either NBI 35965 (CRF-R1 antagonist; $1 \mu \mathrm{m}$; top) or Astressin 2B (CRF-R2 antagonist; $300 \mathrm{~nm}$; bottom). $\boldsymbol{b}$, NAc CIN firing frequency before and after CRF application in each condition. c, Time course of (RF effect on CIN firing frequency normalized to baseline in each condition. $\boldsymbol{d}$, Left, Representative traces, (middle) CIN firing frequency, and (right) the time course of average CIN firing before and after CRF bath application in the presence of NBQX $(20 \mu \mathrm{m}), \mathrm{CPP}(5 \mu \mathrm{M})$, CGP $55845(2 \mu \mathrm{m})$, and gabazine $(5 \mu \mathrm{m}) . \boldsymbol{e}$, Representative voltage traces in response to different amount of current injection recorded from CINs in (top) ACSF or (bottom) ACSF + ZD $7288(1 \mu \mathrm{m}) . \boldsymbol{f}$, Average $I_{\mathrm{h}}$-mediated sag in ACSF or ACSF + ZD 7288. $\boldsymbol{g}$, Left, Representative traces, (middle) CIN firing frequency, and (right) the time course of average before and following CRF application in the presence of ZD 7288 compared with ACSF condition (green line). $\boldsymbol{h}$, Summary of maximal CRF response (\% baseline) for the experiments described in $\boldsymbol{a}-\boldsymbol{g}$. ${ }^{* * *}$, denotes statistical significance $p<0.001, t$-test; \#\#\#\#\# denotes statistical significance $p<0.01,0.001$ respetively for 1- and 2-way ANOVAs. n.s. denotes no statistical significance.

As control, we also quantified Crh1 and Crh2 mRNA expression in cholinergic projection neurons of the basal forebrain from the same brain sections. Substantial literature indicates CRF-R1 expression in cholinergic neurons of the basal forebrain (Sauvage and Steckler, 2001). Analysis of ChAT + neurons in the diagonal band area, where most cholinergic neurons that project to the hippocampus are found (Ballinger et al., 2016), showed 45\% of ChAT+ cells were also colabeled for Crh1 mRNA while only 1\% were colabeled for Crh2 mRNA (Fig. $3 f, g$ ). In the diagonal band/ basal forebrain region, 25\% of all DAPI cells expressed Crh1 mRNA while only 7\% of all DAPI cells expressed Crh2 mRNA (Fig. 3h). Thus, to our surprise, CRF-R1 expression is even more prominent and robust on CINs within the striatum than on cholinergic neurons in the basal forebrain.

\section{CRF-mediated increase in CIN firing requires CRF-R1 activation}

In light of the strong evidence that CINs express CRF-R1 receptors, we hypothesized that the CRF increase of CIN firing is me- diated by direct activation of these receptors on CINs. We focused our experiments in the NAc and tested the ability of the selective antagonists for CRF-R1 and CRF-R2 to block the CRF effect. Slices were pre-incubated with either antagonist for at least $20 \mathrm{~min}$ and maintained in the antagonist for the duration of the experiment. In the presence of the CRF-R1 antagonist NBI 35695 $(1 \mu \mathrm{M})$, CRF failed to increase CIN firing frequency. We also tested a different R1 antagonist, CP 154,526 (1 $\mu \mathrm{M})$, which also reduced the effect of CRF, although did not block it completely. In contrast, the R2 antagonist Astressin 2B (300 nM) had no effect on the potentiation by CRF (195\% increase from baseline; NBI: $2.6-2.2 \mathrm{~Hz}$; Astressin 2B: $2.1-4.8 \mathrm{~Hz}$, two-way RM ANOVA; interaction: $F_{(1,11)}=$ 47.27, post hoc Sidak's $t$ test for AS2B, $p<0.0001, n=6-7$; Fig. $4 a-c)$. (DMSO vehicle vs CP154,526, two-way RM ANOVA, interaction: $F_{(27,243)}=5.714, p<0.0001, n=5-6$, data not shown.) These pharmacological experiments show that CRF-R1 activation is required for the CRF induced increase in CIN firing.

To further demonstrate a direct effect on R1 receptors expressed on CINs, we tested whether receptor blockers for the 
classical fast acting neurotransmitters glutamate and GABA could prevent the CRF increase of firing. We found that the effect of CRF on CINs persisted in the presence of antagonists for GABA-A (gabazine, $5 \mu \mathrm{M}$ ), GABA-B (CGP 55845, $2 \mu \mathrm{M}$ ), NMDA (CPP, $5 \mu \mathrm{M}$ ), and AMPA (NBQX, $20 \mu \mathrm{M}$ ) receptors, indicating the CRF effect does not require glutamate nor GABA transmission (in the antagonists: $2.9-5.9 \mathrm{~Hz}$, paired $t$ test, $p<0.0001$; two-way RM ANOVA compared with in ACSF: $F_{(27,486)}=$ $0.7891, p=0.7680, n=11$; Fig. $4 d$ ). These pharmacological findings, together with the evidence that CINs express CRF-R1 receptors, strongly indicate that CRF increase of CIN firing is a direct effect downstream of activation of CRF-R1 expressed on CINs.

The next set of experiments attempt to address the channels involved. Previous work by Wanat et al. (2008)showed that CRF enhances the tonic firing of VTA dopamine neurons by increasing $I h$ conductance through a PKC dependent mechanism. Because striatal CINs show similar pacemaker properties as VTA dopamine neurons in an ex vivo slice preparation, it seemed plausible that CRF-R1s in CINs may be using a similar mechanism. We first verified that pre-incubation with the blocker ZD 7288 (1 $\mu \mathrm{M})$ can effectively reduce $\mathrm{I} h$ conductance in CINs by measuring the hyperpolarization-induced "sag" in current-clamp configuration. Note, higher concentrations of ZD $7288(10-20 \mu \mathrm{M})$ cause the cell to stop firing and/or disrupt the gigaohm seal. In the presence of $1 \mu \mathrm{M}$ ZD 7288, $T h$ was reduced from $7.2 \pm 0.1$ to $-0.5 \pm 0.5 \mathrm{mV}$ ( $t$ test, $p<0.0001, n=11-12$; Fig. $4 e, f)$. However, CRF significantly increased CIN firing in slices incubated in this same concentration of ZD 7288 (2.9 \pm 0.4 in baseline to $5.2 \pm 0.5 \mathrm{~Hz}$ after CRF; paired $t$ test, $p=0.0007, n=11$; Fig. $4 g$ ). It is worth mentioning that there was a significant difference in the time course of the CRF effect after ZD 7288 compared with the ACSF condition (two-way RM ANOVA, interaction: $F_{(25,450)}$ $=2.6, p<0.0001, n=9-11$; Fig. $4 g$ ). Yet, when analyzing the mean maximal effect of CRF in ACSF control conditions compared with ZD 7288 conditions, there was no significant difference (ACSF: $153 \pm 22 \%$ increase from baseline; ZD 7288: $95 \pm$ $25 \%$ increase from baseline, one-way ANOVA, Dunnett's post hoc $t$ test, $p=0.3531, n=9-11$; Fig. $4 h$ ). These data suggest that Ih conductance is not a main effector in the CRF-mediated increase of CIN firing. Overall, when assessing all pharmacological blockers together in the cell-attached experiments, only the CRF-R1 antagonist NBI 35695 showed a significantly reduction of CRF action on CINs (one-way ANOVA, Dunnett's post hoc $t$ test, $p=0.003$; Fig. $4 h$ ).

\section{CRF reduces spike accommodation in CINs, which requires cAMP production}

Current-clamp recordings were performed in whole-cell configuration to gain better access to intracellular space and also measure the different components of CIN excitability, including Ih sag, membrane resistance, accommodation, and depolarization induced block of AP firing (Table 2). Current steps of increasing amplitude were applied from a holding potential of $-70 \mathrm{mV}$ to evoke firing and overcome the hyperpolarization seen after breaking in the cell. CINs showed the canonical spike accommodation in response to the depolarizing current steps where AP frequency was higher during the first $400 \mathrm{~ms}$ (FIRST) than during the last $400 \mathrm{~ms}$ (LAST). The spike accommodation was seen under all conditions: ACSF, VEH, and CRF (two-way RM ANOVAs, interactions: baseline/VEH, $p$ values $<0.0001$; baseline/CRF, $p$ values $<0.0001$; Fig. $5 a-f$ ).
Table 2. Intrinsic properties across drug treatments

\begin{tabular}{|c|c|c|c|c|}
\hline Incubation & $I_{H}$ sag, mV & $\begin{array}{l}\text { Holding } \\
\text { RMP, mV }\end{array}$ & $\mathrm{Rm}, \mathrm{M} \Omega$ & $\begin{array}{l}\text { Significant time } \times \text { drug effect } \\
\text { on baseline } 1 / 0 \text { curve comparec } \\
\text { to baseline ACSF/VEH, } 800 \text { ms }\end{array}$ \\
\hline \multicolumn{5}{|l|}{ ACSF } \\
\hline Baseline & $10.5 \pm 1.2$ & $-71.4 \pm 0.7$ & $285.2 \pm 34.4$ & \\
\hline VEH & $8.0 \pm 1.7^{a}$ & $-70.3 \pm 0.9$ & $249.3 \pm 43.8$ & \\
\hline \multicolumn{5}{|l|}{ ACSF } \\
\hline Baseline & $9.8 \pm 1.1$ & $-70.1 \pm 0.2$ & $223.7 \pm 21.0$ & No difference, $p=0.9360$ \\
\hline CRF & $7.2 \pm 1.1^{a}$ & $-69.5 \pm 0.4$ & $188.3 \pm 20.5$ & \\
\hline \multicolumn{5}{|l|}{ ZD7288 } \\
\hline Baseline & $0.6 \pm 0.4^{b}$ & $-71.5 \pm 0.5$ & $340.0 \pm 36.4 \#$ & No difference, $p=0.5111$ \\
\hline CRF & $-0.5 \pm 0.5^{b}$ & $-70.2 \pm 0.7$ & $332.0 \pm 53.1 \#$ & \\
\hline \multicolumn{5}{|l|}{ Apamin } \\
\hline Baseline & $8.6 \pm 1.1$ & $-73.1 \pm 1.1$ & $193.0 \pm 13.0$ & Decrease, $p=0.0004$ \\
\hline CRF & $6.9 \pm 0.9$ & $-71.6 \pm 0.7$ & $180.5 \pm 33.2$ & \\
\hline \multicolumn{5}{|l|}{ Rp-cAMPs } \\
\hline Baseline & $5.9 \pm 1.3$ & $-68.7 \pm 0.5$ & $147.6 \pm 22.5$ & No difference, $p=0.8730$ \\
\hline CRF & $3.9 \pm 1.1$ & $-69.5 \pm 0.4$ & $126 \pm 14.2$ & \\
\hline \multicolumn{5}{|l|}{ PKI 14-22 } \\
\hline Baseline & $8.8 \pm 1.2$ & $-69.4 \pm 0.5$ & $181.4 \pm 14.6$ & Increase, $p<0.0001$ \\
\hline CRF & $7.3 \pm 1.4$ & $-69.1 \pm 0.5$ & $190.6 \pm 14.4$ & \\
\hline \multicolumn{5}{|l|}{ Chelrythrine } \\
\hline Baseline & $10.3 \pm 1.8$ & $-70.1 \pm 0.6$ & $233.1 \pm 35.8$ & No difference, $p>0.9999$ \\
\hline CRF & $10.9 \pm 2.7$ & $-68.7 \pm 0.7$ & $268.0 \pm 42.9$ & \\
\hline \multicolumn{5}{|l|}{ Go 6983} \\
\hline Baseline & $8.5 \pm 1.2$ & $-69.8 \pm 0.6$ & $261.4 \pm 50.2$ & No difference, $p=0.2971$ \\
\hline CRF & $8.1 \pm 1.6$ & $-68.3 \pm 1.0$ & $298.3 \pm 60.5$ & \\
\hline
\end{tabular}

${ }^{a}$ Sidak's post hoc $t$ test: baseline versus VEH/CRF.

${ }^{b}$ Sidak's post hoc test: drug incubation versus ACSF.

With vehicle application, there was no significant change in AP frequency during the entire $800 \mathrm{~ms}$ step, first half nor last half of the current step (two-way RM ANOVA, $p$ values $=0.99,0.99$, 0.98 , respectively, $n=9$; Fig. $5 a-c$ ). In contrast, CRF application increased AP frequency when averaged for the whole $800 \mathrm{~ms}$ as well as for the first and last half (two-way RM ANOVA, $p$ values $<$ $0.0001, n=12$; Fig. $5 d-f)$. The CRF increase was most prominent during the last $400 \mathrm{~ms}$. The inverse of the slope (1/slope) of the input-output curves is a measure of the magnitude of current needed to generate a single action potential. CRF significantly decreased the 1/slope for the LAST half of the current step from 49 to $27 \mathrm{pA} /$ spike while vehicle application had no effect (CRF: from 20 and $15 \mathrm{pA} /$ spike for FIRST; VEHICLE: from 18 to 17 $\mathrm{pA} /$ spike for FIRST; from 54 to $64 \mathrm{pA} /$ spike for LAST). The steeper slope measured in the presence of CRF may reflect its actions on relieving the depolarization-induced block of AP firing, which is more prominent during the last $400 \mathrm{~ms}$ of the current step. Furthermore, CRF did not enhance the $I h$-mediated sag compared with its own baseline or VEH (Table 2). Consistent with our previous findings from cell-attached recordings, preincubation with the $I h$ inhibitor ZD 7288 had a modest effect. ZD 7288 mainly affected the robustness and reliability of the CRF increase of AP frequency during the last $400 \mathrm{~ms}$ when spike accommodation is most prominent (FIRST $400 \mathrm{~ms}$ : two-way RM ANOVA, $F_{(7,63)}=2.328, p=0.0354$; LAST: two-way RM ANOVA, $F_{(7,63)}=1.1, p=0.3740, n=10$; Fig. $\left.5 g-i\right)$. This indicates that $I h$ current is not required for CRF actions on CINs.

CRF has been shown to enhance the conductance of small conductance calcium-dependent potassium channels (SK) in VTA dopamine neurons, albeit via activation of CRF-R2s (Riegel and Williams, 2008). Moreover, CIN tonic firing is thought to be driven in part by SK channels, which mediate the medium duration afterhyperpolarization (Goldberg et al., 2009). Thus, we tested the effect of the SK channel blocker apamin (300 nM), 
in ACSF

a

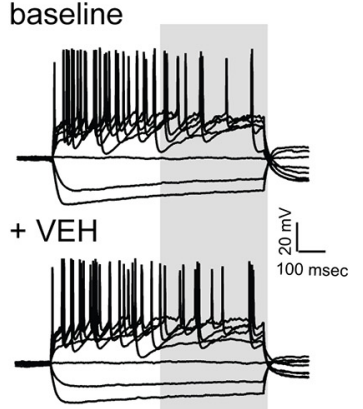

in ACSF

d baseline
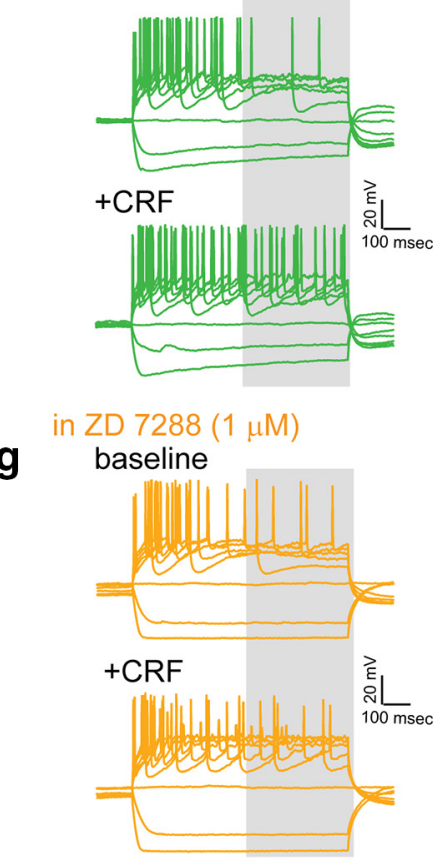

in apamin (300 $\mathrm{nM})$

j

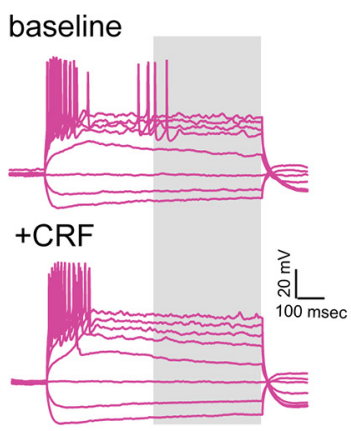

b

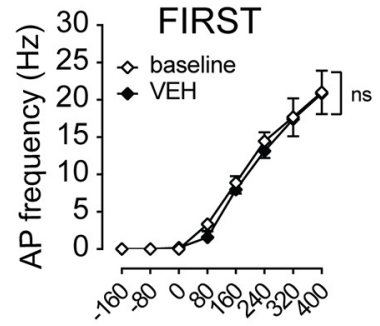

Current injection (pA)
C

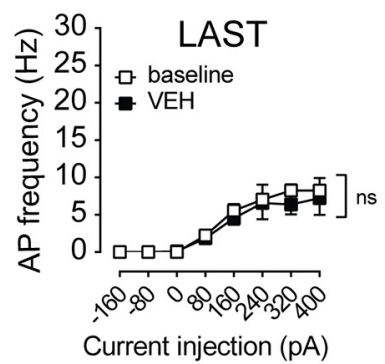

f

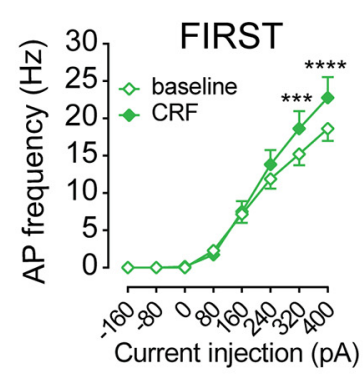

h

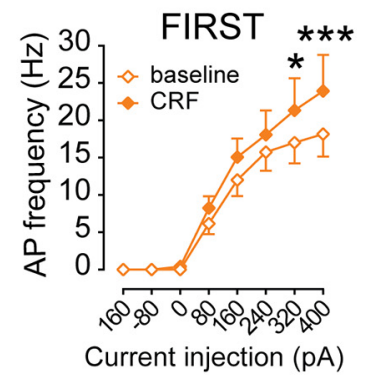

k

FIRST

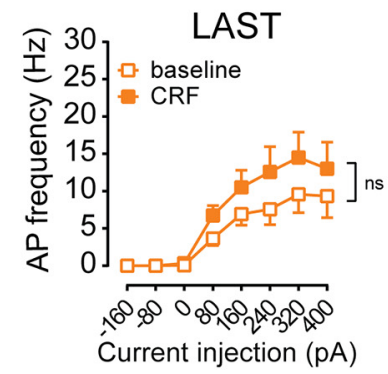

I

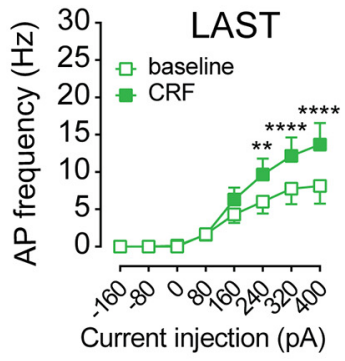

i

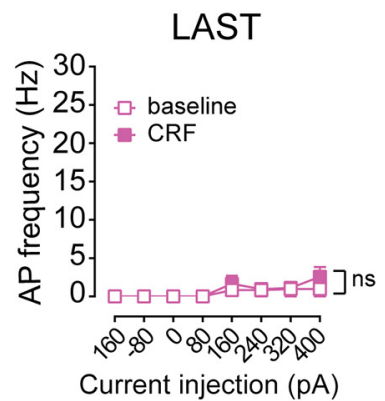

Figure 5. CRF reduces spike accommodation in CIN which is attenuated by sK channel blockade. $\boldsymbol{a}$, Representative voltage traces recorded from striatal CIN in response to current injections ( -160 to $400 \mathrm{pA},+80 \mathrm{pA}$ steps) before and after vehicle application. $\boldsymbol{b}$, Average input-output response of NAc CINs for the first $400 \mathrm{~ms}$ of an $800 \mathrm{~ms}$ sweep before and after vehicle application. $\boldsymbol{c}$, Average input-output response of NAc CINs for the last $400 \mathrm{~ms}$ of an $800 \mathrm{~ms}$ sweep before and after vehicle application. $\boldsymbol{d}$, Representative striatal CIN voltage response to depolarizing current injections $(-160$ to $400 \mathrm{pA}$ ) before and after CRF application. $\boldsymbol{e}$, Average input/output response of NAc CINs for the first $400 \mathrm{~ms}$ of an $800 \mathrm{~ms}$ sweep before and after CRF application. $f$, Average input- output response of NAc CINs for the last $400 \mathrm{~ms}$ of an $800 \mathrm{~ms}$ sweep before and after CRF application. $\boldsymbol{g}$ - $\boldsymbol{i}$, Representative voltage traces $(\boldsymbol{g})$, input- output response for first $400 \mathrm{~ms}(\boldsymbol{h})$, and last $400 \mathrm{~ms}(\boldsymbol{i})$ before and following CRF application in the presence of ZD 7288. $j-I$, Representative voltage traces (j), input- output response for first $400 \mathrm{~ms}(\boldsymbol{k})$ and last $400 \mathrm{~ms}(\boldsymbol{I})$ before and following (RF application in the presence of apamin. ns denotes no statistical significance; asterisks denote statistical significance with $p<0.05\left(^{*}\right), p<0.01\left(^{* *}\right)$ and $p<0.001$ (**) $^{* *}$ for corrected post-hoc $t$-test; and \# denotes a significant interaction by 2-way RM ANOVA. 


\section{Cell attached}
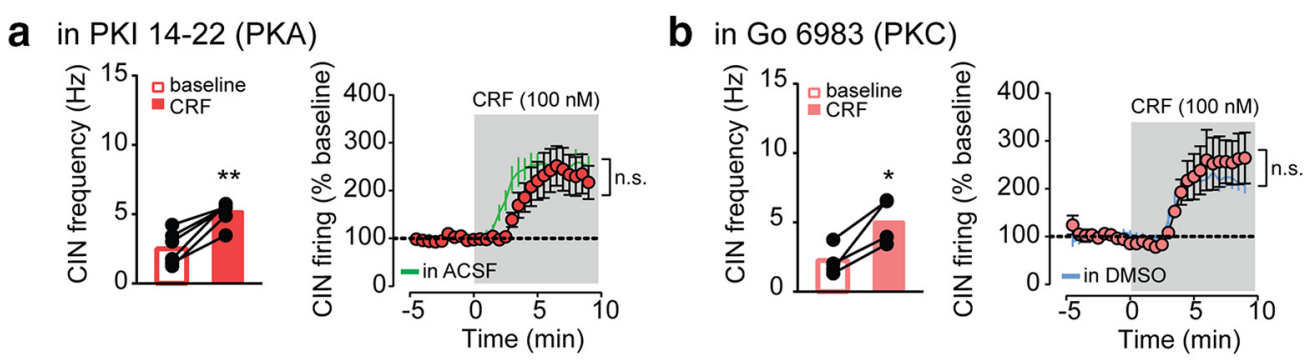

\section{Whole cell current clamp}
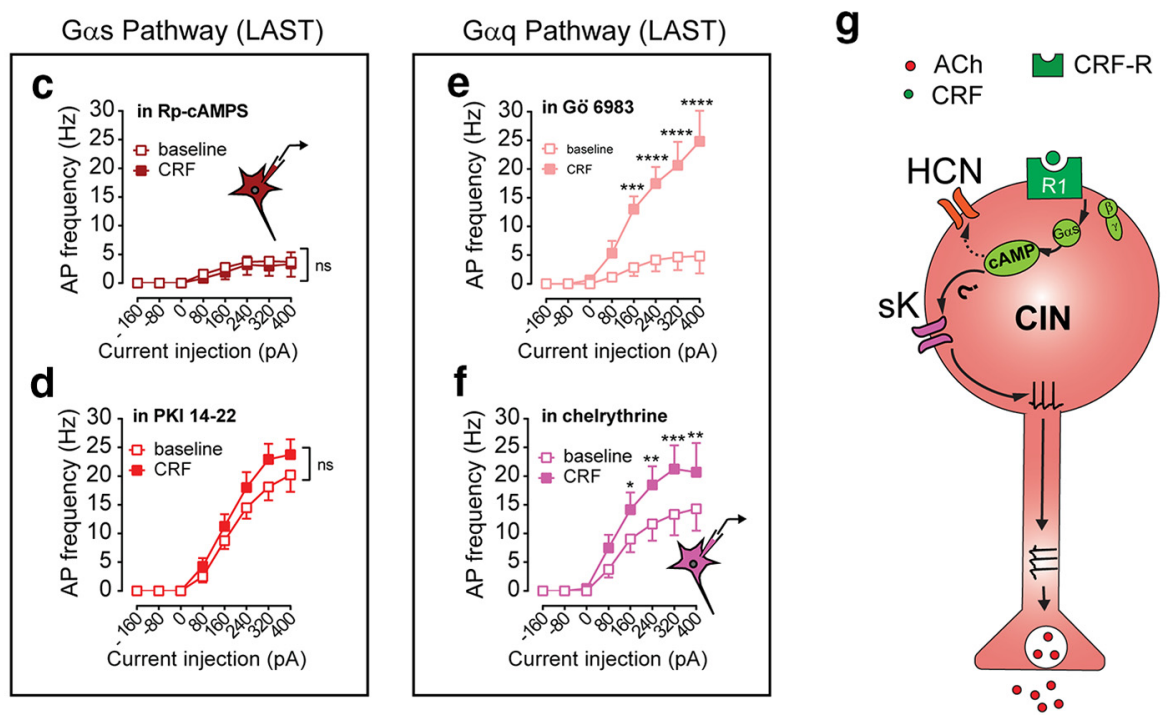

Figure 6. CRF-mediated increase in CIN firing requires CAMP production. $\boldsymbol{a}$, Left, CIN firing frequency (cell attached configuration) and (right) the time course of average before and following CRF application in the presence of PKI 14-22. $\boldsymbol{b}$, Left, CIN firing frequency (cell attached configuration) and (right) the time course of average before and following (RF application in the presence of Go 6983. c $\boldsymbol{f}$, In current-clamp, average input/output curve (last $400 \mathrm{~ms}$ ) for CINs recorded before and following CRF (100 nm) bath application in cells with Rp-cAMPS present in the internal solution (c), slices incubated and maintained in PKI 14-22 (d), in slices incubated and maintained in G0 6983 (e) and cells with chelrythrine present in the internal solution $(\boldsymbol{f})$. $\boldsymbol{g}$, Summary diagram detailing the mechanism by which CRF increases (IN firing. Asterisks denote statistical significance $p<0.05\left(^{*}\right), p<0.01\left(^{* *}\right)$ and $p<0.001\left(^{* * *}\right)$ for corrected post-hoc $t$-tests. n.s. denotes no statistical significance.

which unlike the low dose of $\mathrm{ZD} 7288$, induced a significant reduction of AP firing frequency in CINs (two-way RM ANOVA, main effect of drug, apamin: $F_{(2,25)}=4.084, p=0.0292, n=6$; ZD 7288: $\left.F_{(1,20)}=0.04529, p=0.8336, n=10\right)$. Nevertheless, apamin fully prevented the CRF increase of AP frequency during the LAST $400 \mathrm{~ms}$ of the current step but had no effect on the FIRST 400 ms (FIRST: two-way RM ANOVA, $F_{(7,35)}=2.69, p=$ 0.0244; LAST: two-way RM ANOVA, $F_{(7,35)}=0.4849, p=$ $0.8389, n=6$; Fig. $5 j-l$ ). This result shows that indeed SK channels plays a role in regulating spike accommodation in CINs and suggest that they are required for CRF-mediated suppression of this phenomenon.

It has been demonstrated that CRF receptors can couple to both $\mathrm{G} \alpha$ s and $\mathrm{G} \alpha \mathrm{q}$ proteins which trigger the activation of PKA and PKC pathways, respectively (Hauger et al., 2009). Surprisingly, the increase in CIN firing frequency measured in cellattached configuration was unaffected by bath application of inhibitors of PKA (PKI 14-22; $1 \mu \mathrm{M}$ ) or PKC (Go 6983; $3 \mu \mathrm{M})$. In the presence of PKI 14-22, CRF increased firing from $2.5 \pm 0.5$ to $5.1 \pm 0.8 \mathrm{~Hz}$ (paired $t$ test, $p=0.002$; two-way RM ANOVA compared with ACSF, interaction: $F_{(27,351)}=1.17, p=0.26, n=$ 6; Fig. $6 a$ ) and in Go 6983, CRF increased firing from $2.2 \pm 0.5$ to $5.1 \pm 0.8 \mathrm{~Hz}$ (paired $t$ test, $p=0.02$; two-way RM ANOVA compared with DMSO, interaction: $F_{(27,189)}=0.7591, p=$ 0.7792, $n=4-5$; Fig. 6b).

We turned to current-clamp whole-cell configuration to examine different components of CIN excitability (Table 2) and test pharmacological inhibitors that are membrane impermeable and need to be introduced in the internal solution via the recording electrode. To probe the requirement for $\mathrm{G} \alpha$ s signaling, we introduced an inert cAMP analog (Rp-cAMPs; $100 \mu \mathrm{M}$ ) to block cAMP-dependent signaling and also tested a PKA inhibitor, PKI $14-22$, in separate experiments. In the presence of these blockers for $\mathrm{G} \alpha$ s signaling pathways, CRF was unable to increase AP firing during the last $400 \mathrm{~ms}$ of the current pulse, suggesting an involvement of cAMP-dependent and PKA-dependent signaling particularly when spike accommodation is occurring (two-way RM ANOVA, interaction: Rp-cAMPs: $p=0.9857, n=7$, Fig. $6 c$; PKI 14-22: $p=0.2201, n=8$, Fig. $6 d$ ), downstream of G $\alpha$ s. Please note that in the presence of PKI 14-22 alone, AP firing was increased from control during the last $400 \mathrm{~ms}$, which could be occluding the CRF effect (Table 2). However, it should also be noted that in the presence of PKI 14-22 CRF still significantly enhanced AP frequency during the first $400 \mathrm{~ms}$, suggesting that the lack of effect on the last $400 \mathrm{~ms}$ is not because of a ceiling effect on firing (two-way RM ANOVA, interaction: $p=0.0001, n=8$, 
data not shown). This could explain why we are still able to see a significant CRF effect, albeit more variable, in the cell-attached experiments. Thus, although we conclude that CRF modulation of CIN firing requires $\mathrm{G} \alpha$ s signaling and cAMP production, we are cautious when concluding on involvement of PKAdependent signaling.

We also tested two different PKC inhibitors, chelrythrine (3 $\mu \mathrm{M})$ in the internal solution and Go $6983(1 \mu \mathrm{M})$ applied to the bath. CRF robustly enhanced AP frequency over a range of depolarizing currents regardless of how we looked at the sweep in the presence of chelrythrine or Go 6983 (two-way RM ANOVA, interaction: $p$ values $=0.0025$ and 0.0001 ; main effect of CRF: $p$ values $=0.02,0.009$ for chelrythrine and Go 6983, respectively; Sidak's post hoc $t$ tests with ${ }^{\star} p<0.05,{ }^{* *} p<0.01,{ }^{* * *} p<0.001$, ${ }^{* * * *} p<0.0001, n=5-6$; Fig. $\left.6 e, f\right)$.

Together, these data indicate that CRF enhances CIN firing through multiple effectors, all of which rely on cAMP. The effect of CRF seems to be particularly prominent when measuring the AP frequency when the depolarization induced block common to CINs is most apparent. PKA and Ih may play a modest role and may be necessary for CRF to achieve its typical reliable and maximal effect size, however it is not required for the effect to occur. SK channel activation appears to play a role in the CRF-mediated suppression of spike accommodation. Based on both the cellattached voltage-clamp and current-clamp experiments, it does not appear that the CRF-mediated increase in CIN firing frequency is reliant on PKC activation (Fig. $6 g$ ).

\section{CRF potentiation of DA transmission is independent of nicotinic acetylcholine receptor activation}

We speculated that CRF increase in CIN firing leads to enhanced acetylcholine release which could potentiate of DA transmission via activation of acetylcholine receptors on the axons of DA neurons. Both nicotinic and muscarinic receptors have been shown to modulate DA transmission (Threlfell et al., 2012; Shin et al., 2015, 2017; Brimblecombe and Cragg, 2017) and we hypothesized that both could be playing a role in the CRF-mediated potentiation of DA transmission. Using fast scan cyclic voltammetry in the same ex vivo slice preparation used before, we first replicated the main finding that CRF potentiates the peak amplitude of the evoked DA transient by $21 \pm 4 \%$ above baseline (onesample $t$ test vs $0, p=0.003, n=16$; Fig. $7 a, d, h)$, and is significantly greater than after vehicle control (two-way RM ANOVA, interaction of CRF vs VEH: $F_{(13,338)}=5.014, p<0.0001, n=$ 12-16; Fig. $7 d$ ). (Note that separate time-matched vehicle controls were run for every pharmacological and/or genetic manipulation condition.)

Application of a blocker for $\beta 2$-containing nicotinic receptors, $\mathrm{DH} \beta \mathrm{E}(1 \mu \mathrm{M})$, on its own, reduced the amplitude of DA transients evoked by electrical stimulation ( $\mathrm{eDA}$ ) by $>50 \%$. This pharmacological treatment isolates one of the components of eDA "composite" transient that is independent of nAChRs and mediated by direct activation of DA axon fibers in the striatum (Zhang et al., 2002; Shin et al., 2015). However, in the presence of $\mathrm{DH} \beta \mathrm{E}, \mathrm{CRF}$ still potentiated eDA transients by $34 \pm 6 \%$ (onesample $t$ test vs $0, p<0.0001, n=16$, two-way RM ANOVA vs $\mathrm{VEH}$, interaction: $F_{(13,273)}=7.082, p<0.0001, n=7-16$; Fig. $7 b, d, h)$. When we probed this further using a train of 5 pulses of electrical stimulation at $10 \mathrm{~Hz}$, a frequency closely resembling that of in vivo phasic DA neuron burst firing, the CRF potentiation of DA transients was significantly larger in the presence of $\mathrm{DH} \beta \mathrm{E}$ than ACSF (ACSF: $8.7 \pm 4.6 \%$ increase for $5 \mathrm{p} / 10 \mathrm{~Hz}$; $\mathrm{ACSF}+\mathrm{DH} \beta \mathrm{E}: 34.5 \pm 5.1 \%$ increase, $\# \#$ \# $<0.001$ for Sidak's post hoc $t$ test following two-way RM ANOVA with significant interaction $p<0.05, n=11-12$ ). This seemed due to a marked reduction in CRF potentiation of DA transmission in ACSF compared with $1 \mathrm{p}$ stimulation, though this was not significant ( $1 \mathrm{p}$ vs $5 \mathrm{p} / 10 \mathrm{~Hz}: 20.8 \pm 4.6 \%$ vs $8.7 \pm 4.6 \%$, Sidak's post hoc $t$ test, $p=$ $0.09)$.

Thus, the nAChR antagonist was unable to block the CRF potentiation but rather seems to facilitate this CRF effect during certain stimulation conditions. These results indicate that activation of $\mathrm{nAChR}$ is not required for the CRF-mediated potentiation of DA transmission.

\section{CRF potentiation of dopamine transmission is dependent on M5 receptor activation}

We and others have previously shown that activation of muscarinic M5 receptors potentiate DA transmission, particularly when DA release is triggered by activation of DA fibers optogenetically or electrically in the presence of nicotinic antagonists (Zhang et al., 2002; Schmidt et al., 2010; Shin et al., 2015). We tested whether the activation of $\mathrm{mAChR}$ is required for CRFmediated potentiation of DA transients. Scopolamine $(1 \mu \mathrm{M})$, a nonselective $\mathrm{mAChR}$ antagonist, reduced the CRF-mediated potentiation by $50 \%$, both in control ACSF and in $\mathrm{DH} \beta \mathrm{E}$ conditions (in ACSF + SCOP: CRF vs VEH: two-way RM ANOVA, interaction: $F_{(13,386)}=2.158, p=0.01, n=6-16$; Fig. $7 f, h, i$; in $\mathrm{DH} \beta \mathrm{E}+\mathrm{SCOP}$ : CRF vs VEH: two-way RM ANOVA, interaction: $\left.F_{(13,281)}=4.567, p<0.0001, n=11-13\right)$. Although smaller, CRF still showed a significant potentiation of eDA compared with vehicle. These data suggest that activation of muscarinic receptors mediates a part, but not all of, the CRF potentiation of DA transmission.

In mice with constitutive genetic deletion of M5 receptors ( $\mathrm{M} 5 \mathrm{KO})$, there was a reduction of the CRF potentiation of DA transient compared with control mice, confirming that these receptors are involved. The reduction was similar to that observed in control mice after the blockade of $\mathrm{mAChR}$ with scopolamine (control $=20.6 \pm 4.4 \%, \mathrm{M} 5 \mathrm{KO}=8.25 \pm 2.6 \%$; $\mathrm{SCOP}=7.85 \pm$ $2.2 \%$, one-way ANOVA, $F=4.49, p=0.017$, post hoc $t$ test vs control: $p$ values $=0.019,0.035$ for SCOP or M5KO respectively, post hoc $t$ test SCOP vs M5KO, $p=0.9998, n=13-16$; Fig. $7 g, h$ ). Furthermore, in the presence of $\mathrm{DH} \beta \mathrm{E}, \mathrm{M} 5 \mathrm{KO}$ mice still showed a reduced potentiation by CRF (in $\mathrm{DH} \beta \mathrm{E}$ : control $=34.0 \pm$ $5.6 \%, \mathrm{M} 5 \mathrm{KO}=16.2 \pm 2.1 \%, \mathrm{SCOP}=14.9 \pm 2.7 \%$, one-way ANOVA, $F=5.55, p=0.008$, post hoc $t$ test vs control: $p$ values $=$ $0.009,0.037$ for SCOP or M5KO respectively, post hoc $t$ test SCOP vs $\mathrm{M} 5 \mathrm{KO}, p=0.9846, n=8-16$; Fig. $7 i$ ). Again, in ACSF or $\mathrm{DH} \beta \mathrm{E}$ conditions, CRF had a smaller, but still significant effect of DA transient peak amplitude compared with vehicle control in M5KO mice (ACSF, CRF vs VEH: two-way RM ANOVA, interaction: $F_{(13,260)}=2.609, p=0.0020, n=10-12$; DH $\beta E$, CRF vs VEH: two-way RM ANOVA, interaction: $F_{(13,130)}=2.884, p=$ $0.0011, n=4-8$ ).

As a control, we tested whether the antagonist for $\mathrm{nAChR}$ or mAChRs altered the CRF increase in CIN firing. CRF significantly increased CIN spontaneous firing in the presence of the nAChR blocker DH $\beta$ E (in DH $\beta$ E: from $2.45 \pm 0.26$ to $5.71 \pm$ $0.46 \mathrm{~Hz}$ after CRF, $p<0.0001, n=14$; Fig. $7 k, l)$ or $\mathrm{mAChR}$ blocker scopolamine (in scopolamine: from $2.8 \pm 0.35 \mathrm{~Hz}$ to $5.3 \pm 0.38$ after CRF, $p<0.0001, n=11$; Fig. $7 m, n)$. Neither $\mathrm{DH} \beta \mathrm{E}$ nor the $\mathrm{mAChR}$ scopolamine significantly reduced the maximal CRF-mediated increase in CIN firing frequency (Maximal effect: ACSF: $153.2 \pm 22.5 \%$, DH $\beta$ E: $151.6 \pm 21.4 \%$, Scopolamine: $110.8 \pm 17.9 \%$ increase over baseline, one-way 


\section{a in ACSF}



d in ACSF

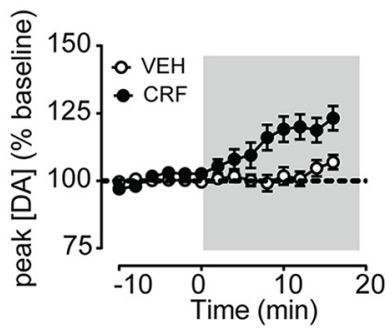

f in SCOPOLAMINE

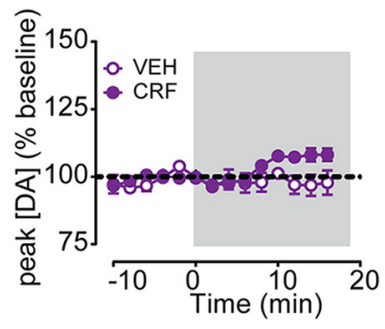

j Nucleus Accumbens

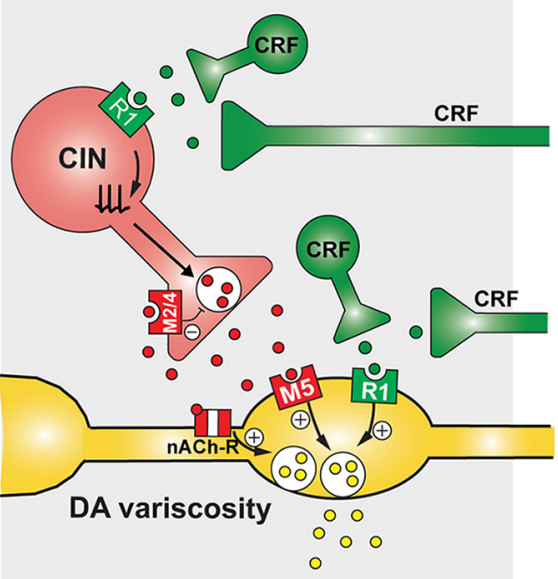

CRF

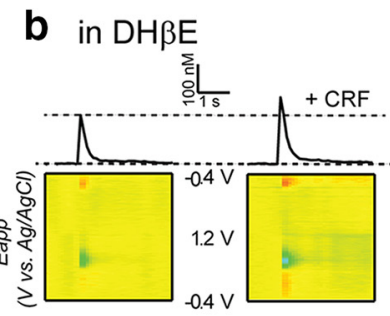

e in $\mathrm{DH} \beta \mathrm{E}$

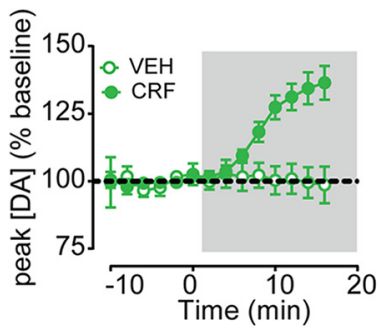

g in ACSF, M5KO

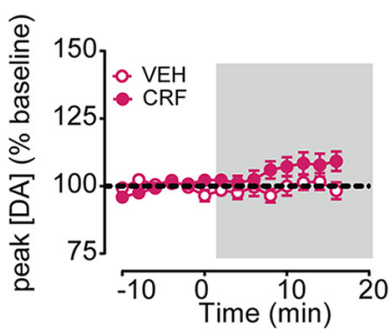

CIN Recordings



$\mathbf{m}_{\text {baseline }}$

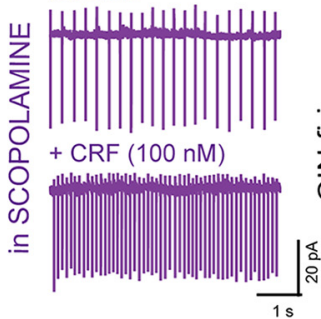

C in SCOPOLAMINE

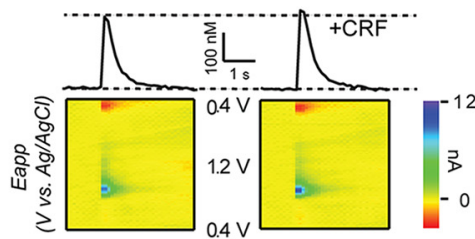

h

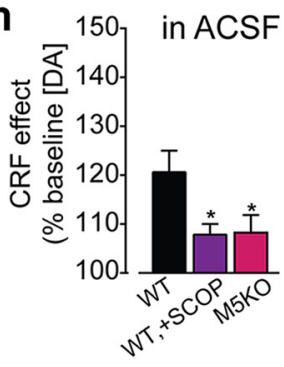

i

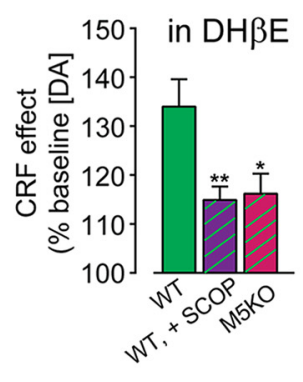



n

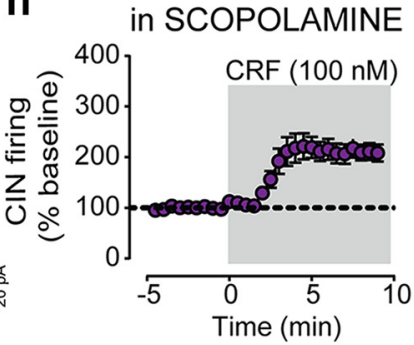

Figure 7. CRF potentiation of DA transmission requires mACh-R type 5 receptor activation. $\boldsymbol{a}$, Representative current-time traces and corresponding 3-D color plots of electrically evoked dopamine transients before and following CRF application in slices maintained in ACSF $(\boldsymbol{a})$, ACSF $+\operatorname{DH} \beta E(1 \mu \mathrm{m} ; \boldsymbol{b})$, ACSF + Scopolamine $(1 \mu \mathrm{m} ; \boldsymbol{c})$. $\boldsymbol{d}$, Mean time course of electrically evoked DA transients recorded before or after CRF or vehicle application in WT control NAc slices incubated and maintained in ACSF. $e$, Mean time course of electrically evoked DA transients recorded before or after CRF or vehicle application in WT control (in-house (57BI/6J) NAc slices incubated and maintained in ACSF + DH $\beta$ E. $f$, Mean time course of electrically evoked DA transients recorded before or after CRF or vehicle application in WT control NAc slices incubated and maintained in ACSF + Scopolamine. $\boldsymbol{g}$, Mean time course of electrically evoked DA transients recorded before or after CRF or vehicle application in M5KO NAc slices incubated and maintained in ACSF. $\boldsymbol{h}$, Average maximal CRF effect on peak [DA] (\% baseline) in experiments conducted in ACSF. $\boldsymbol{i}$, Average maximal CRF effect on peak [DA] (\% baseline) in experiments conducted in ACSF + DH $\beta$ E. $\boldsymbol{j}$, Schematic of CRF function in the NAc under normal conditions. $\boldsymbol{k}, \boldsymbol{I}$, Representative traces $(\boldsymbol{k})$ and normalized time course (I) of NAc CINs before and following CRF application in slices incubated and maintained DH $\beta E$. $\boldsymbol{m}, \boldsymbol{n}$, Representative traces $(\boldsymbol{m})$ and normalized time course $(\boldsymbol{n})$ of NAc CINs before and following CRF application in slices incubated and maintained scopolamine. Asterisks denote statistical significance $p<0.05\left({ }^{*}\right)$ and $p<0.01\left({ }^{* *}\right)$. 
ANOVA compared with ACSF, $\left.F_{(2,31)}=1.28, p=0.2919\right)$. $\mathrm{DH} \beta \mathrm{E}$, however, slightly delayed the time to maximal CRF effect (two-way RM ANOVA compared with in ACSF, $F_{(27,567)}=2.62$, $p<0.0001, n=14$; Fig. $7 l$ ).

Altogether, these data indicate that CRF effects are independent of $\mathrm{nAChR}$ activation and that activation of M5 mAChRs is required for the DA transient potentiation. The latter is consistent with the evidence for M5 mAChR localization to DA axon projections and/or terminals and in agreement with previous work (Shin et al., 2015). This work also provides strong evidence that M5 mAChR-dependent potentiation of DA transmission is downstream of CRF activation of $\mathrm{R} 1$ receptors on CINs and the increase in CIN firing. Thus, it is revealed that there are two independent mechanisms for CRF-mediated potentiation of DA transmission: one that requires activation of $\mathrm{M} 5 \mathrm{mAChR}$ receptors and another that is independent of these receptors and likely mediated direct activation of CRF receptors on dopamine terminals, supported also by previous anatomical data (Lemos et al., 2012).

\section{Discussion}

\section{Novel CRF effector within the striatum: cholinergic interneurons}

This study identifies the cholinergic interneurons in the striatum as a novel target of CRF actions within the dorsal and ventral regions of the striatum. CRF acutely and potently increases the spontaneous firing of CINs by reducing the normal spike frequency accommodation. We show that CINs express CRF-R1 receptors, which are likely to directly mediate this fast effect of CRF via signaling cascades that involved cAMP production. CRF increase in CIN firing facilitates cholinergic transmission, which in turns potentiates the magnitude of DA transients via activation of $\mathrm{M} 5$ receptors. These findings tie together some important, yet disjointed, knowledge on the motivational effect of CRF and the role and interaction of cholinergic and dopaminergic transmission in the striatum.

\section{CRF acts on CINs and increases firing to facilitate cholinergic transmission in the striatum}

Here we show evidence of high degree of colocalization of mRNAs for CRF-R1 and for a marker of CINs, ChAT, in the DS and NAc. A few previous reports showed sparse expression of CRF receptors in the striatum (Van Pett et al., 2000; Justice et al., 2008; Kühne et al., 2012; Henckens et al., 2016) but the cellular identity of this expression had not been addressed. Here we report expression of CRF-R1 receptors in CINs and functional effects of CRF on these neurons. We propose that this novel effect of CRF represents the underlying mechanism for a previously published effect of CRF in the NAc where elevation of ACh extracellular levels was seen in response to CRF (Chen et al. (2012). Acetylcholine release from the basal forebrain versus the striatum supports different, and in some cases opposite behaviors. Both stress and centrally (i.c.v.) administered CRF stimulate acetylcholine release in the hippocampus via activation of CRF-R1 receptors on cholinergic basal forebrain diagonal band projection neurons (Day et al., 1998a,b; Sauvage and Steckler, 2001; Fernandes et al., 2018). Moreover, this enhanced cholinergic transmission and nicotinic receptor activation in the hippocampus can lead to an increase in anxiety- and depression-like behavior (Mineur et al., 2013; Fernandes et al., 2018).

Acetylcholine transmission in the striatum subserves a diverse set of behavioral responses that are dependent on the striatal subregion (i.e., NAc, DLS, DMS) and context in which ACh levels or CIN firing is being assessed. There is evidence that enhanced cholinergic signaling encodes salience regardless of valence and reflects reward prediction errors by shifting from a tonic to burst/ pause mode (Deffains and Bergman, 2015). It has also been shown that modulation of CIN firing can support both approach or withdrawal behavior (Hoebel et al., 2007; Grasing, 2016), is important for reinforcement learning and for cognitive and behavioral flexibility (Ragozzino, 2003; Prado et al., 2017; Aoki et al., 2018). Interestingly, a recent paper by Warner-Schmidt and colleagues demonstrated that silencing CINs promoted withdrawal and immobility in the face of environmental challenge (Warner-Schmidt et al., 2012). This indicates that activation of CINs under certain conditions would promote motivated motor activity and approach behavior.

Here we show that exogenously applied CRF enhances CIN firing frequency regardless of region. Thus, we propose CRF acts to potentiate ACh-dependent striatal behaviors. The specific behavior to be facilitated will depend on the striatal subregion where CRF is released. Regional differences in CRF peptide expression and release should also be considered. For example, as stated in this study, mRNA coding for CRF peptide was found in a small but significant percentage of neurons in the NAc, but not in the DS. This finding is in agreement with previous reports (Merchenthaler, 1984; Peng et al., 2017). In addition, higher density of CRF-containing axonal projections from other brain areas was seen in the NAc compared with the DS. According to both the Allen Brain Atlas as well as a recent study by Itoga et al. (2019), the BLA, BNST, and paraventricular nucleus of the thalamus send prominent CRF-containing projections to the NAc, but not the DS (Oh et al., 2014; Itoga et al., 2019). Thus, endogenously released CRF from CRF + cells or CRF-containing axonal projections to the NAc is predicted to potentiate ACh-dependent behaviors mediated by the NAc. This prediction should be directly tested in future studies.

CRF receptors were shown to couple to different G-proteins depending on cell type and agonist concentration. Here we showed that the CRF-mediated increase in CIN firing requires cAMP production. Yet there was only a nominal effect of PKA or PKC inhibition on CRF's ability to increase firing frequency. It is possible that CRF is exerting its effect on CIN firing through a cAMP dependent, but PKA independent mechanism. Indeed, there have been recent reports that CRF receptors can couple to EPAC2 (a guanine nucleotide exchange factor for the Ras-like small GTPases) in a cAMP-dependent fashion (Traver et al., 2006; Smani et al., 2010; Van Kolen et al., 2010). EPACs have been shown to modulate the function of several different ion channel types including L-type calcium channels, AMPA receptors and voltage-gated potassium channels (Roscioni et al., 2008; Smani et al., 2010; Liu et al., 2016; Stott et al., 2016). Thus, it is plausible that CRF-R1 is stimulating EPACs to affect ion channel conductance and in turn firing frequency at one of these effectors. Moreover, recent work demonstrated that $\mathrm{K}_{\mathrm{v}} 1.3$ ablation in a Parkinson's disease model leads to a reduction of spike accommodation in cholinergic interneurons (Tubert et al., 2016). Therefore, it is also possible that CRF is inhibiting these potassium channels to produce the reduction in spike accommodation.

\section{CRF indirectly activates ACh muscarinic M5 receptors to potentiate dopamine transmission}

Our findings indicate that CRF potentiates dopamine transmission via two independent mechanisms: (1) one that requires activation of ACh M5 receptors and (2) an M5-independent mechanism. Based on the in situ hybridization findings showing expression of Crh1 (coding for CRF-R1 receptors) in the CINs 
and the pharmacological data, we provide evidence that activation of CRF-R1 receptors on CINs causes the increase in spontaneous firing that increases the extracellular levels of Ach which in turn activate muscarinic M5 receptors on DA neuron axon terminals to potentiate DA transmission (Fig. 5). Nonselective muscarinic agonist treatment activates both muscarinic autoreceptors and M5 receptors. In contrast, CRF, even in "ACSF" conditions favors activation of $\mathrm{M} 5$ receptors suggesting that there may be different neurochemical and structural microdomains that house M5 receptors versus M2/M4 receptors.

\section{Concluding remarks}

CINs, although representing a small percentage of striatal neurons, are thought to exert an important modulatory control of the striatal circuitry and its output. The potent and selective effect of CRF on this neuronal cell type further highlights their relevance and opens new questions and lines of research to further understand the behavioral implications of these findings. The M5 receptor is an interesting target for potential therapeutic actions, which unlike other muscarinic receptors it has quite restricted expression. Our data suggest that deletion of M5 receptors very selectively impairs the $\mathrm{CRF}$ actions on dopamine transmission. It is possible that boosting M5 receptor activity, e.g., with a positive allosteric modulator or partial agonist, would have therapeutic value by ameliorating some impairments of dopamine-dependent behaviors such as exploratory and appetitive behaviors.

\section{References}

Abudukeyoumu N, Hernandez-Flores T, Garcia-Munoz M, Arbuthnott GW (2019) Cholinergic modulation of striatal microcircuits. Eur J Neurosci 49:604-622.

Aoki S, Liu AW, Akamine Y, Zucca A, Zucca S, Wickens JR (2018) Cholinergic interneurons in the rat striatum modulate substitution of habits. Eur J Neurosci 47:1194-1205.

Bale TL (2006) Stress sensitivity and the development of affective disorders. Horm Behav 50:529-533.

Bale TL, Vale WW (2004) CRF and CRF receptors: role in stress responsivity and other behaviors. Annu Rev Pharmacol Toxicol 44:525-557.

Ballinger EC, Ananth M, Talmage DA, Role LW (2016) Basal forebrain cholinergic circuits and signaling in cognition and cognitive decline. Neuron 91:1199-1218.

Brimblecombe KR, Cragg SJ (2017) The striosome and matrix compartments of the striatum: a path through the labyrinth from neurochemistry toward function. ACS Chem Neurosci 8:235-242.

Cachope R, Mateo Y, Mathur BN, Irving J, Wang HL, Morales M, Lovinger DM, Cheer JF (2012) Selective activation of cholinergic interneurons enhances accumbal phasic dopamine release: setting the tone for reward processing. Cell Rep 2:33-41.

Chen YW, Rada PV, Bützler BP, Leibowitz SF, Hoebel BG (2012) Corticotropin-releasing factor in the nucleus accumbens shell induces swim depression, anxiety, and anhedonia along with changes in local dopamine/acetylcholine balance. Neuroscience 206:155-166.

Cook CJ (2004) Stress induces CRF release in the paraventricular nucleus, and both CRF and GABA release in the amygdala. Physiol Behav 82:751762.

Day JC, Koehl M, Deroche V, Le Moal M, Maccari S (1998a) Prenatal stress enhances stress- and corticotropin-releasing factor-induced stimulation of hippocampal acetylcholine release in adult rats. J Neurosci 18:18861892.

Day JC, Koehl M, Le Moal M, Maccari S (1998b) Corticotropin-releasing factor administered centrally, but not peripherally, stimulates hippocampal acetylcholine release. J Neurochem 71:622-629.

Deffains M, Bergman H (2015) Striatal cholinergic interneurons and cortico-striatal synaptic plasticity in health and disease. Mov Disord 30: $1014-1025$.

Fernandes SS, Koth AP, Parfitt GM, Cordeiro MF, Peixoto CS, Soubhia A, Moreira FP, Wiener CD, Oses JP, Kaszubowski E, Barros DM (2018) Enhanced cholinergic-tone during the stress induce a depressive-like state in mice. Behav Brain Res 347:17-25.
Goldberg JA, Teagarden MA, Foehring RC, Wilson CJ (2009) Nonequilibrium calcium dynamics regulate the autonomous firing pattern of rat striatal cholinergic interneurons. J Neurosci 29:8396-8407.

Goldberg JA, Ding JB, Surmeier DJ (2012) Muscarinic modulation of striatal function and circuitry. Handb Exp Pharmacol 208:223-241.

Grasing K (2016) A threshold model for opposing actions of acetylcholine on reward behavior: molecular mechanisms and implications for treatment of substance abuse disorders. Behav Brain Res 312:148-162.

Hauger RL, Risbrough V, Oakley RH, Olivares-Reyes JA, Dautzenberg FM (2009) Role of CRF receptor signaling in stress vulnerability, anxiety, and depression. Ann N Y Acad Sci 1179:120-143.

Henckens MJ, Deussing JM, Chen A (2016) Region-specific roles of the corticotropin-releasing factor-urocortin system in stress. Nat Rev Neurosci 17:636-651.

Hoebel BG, Avena NM, Rada P (2007) Accumbens dopamine-acetylcholine balance in approach and avoidance. Curr Opin Pharmacol 7:617-627.

Holly EN, Boyson CO, Montagud-Romero S, Stein DJ, Gobrogge KL, DeBold JF, Miczek KA (2016) Episodic social stress-escalated cocaine self-administration: role of phasic and tonic corticotropin releasing factor in the anterior and posterior ventral tegmental area. J Neurosci. 36:4093-4105.

Itoga CA, Chen Y, Fateri C, Echeverry PA, Lai JM, Delgado J, Badhon S, Short A, Baram TZ, Xu X (2019) New viral-genetic mapping uncovers an enrichment of corticotropin-releasing hormone-expressing neuronal inputs to the nucleus accumbens from stress-related brain regions. J Comp Neurol. Advance online publication. Retrieved March 12, 2019. doi: 10.1002/cne.24676.

Justice NJ, Yuan ZF, Sawchenko PE, Vale W (2008) Type 1 corticotropinreleasing factor receptor expression reported in BAC transgenic mice: implications for reconciling ligand-receptor mismatch in the central corticotropin-releasing factor system. J Comp Neurol 511:479-496.

Kühne C, Puk O, Graw J, Hrabě de Angelis M, Schütz G, Wurst W, Deussing JM (2012) Visualizing corticotropin-releasing hormone receptor type 1 expression and neuronal connectivities in the mouse using a novel multifunctional allele. J Comp Neurol 520:3150-3180.

Laplante F, Dufresne MM, Ouboudinar J, Ochoa-Sanchez R, Sullivan RM (2013) Reduction in cholinergic interneuron density in the nucleus accumbens attenuates local extracellular dopamine release in response to stress or amphetamine. Synapse 67:21-29.

Lemos JC, Wanat MJ, Smith JS, Reyes BA, Hollon NG, Van Bockstaele EJ, Chavkin C, Phillips PE (2012) Severe stress switches CRF action in the nucleus accumbens from appetitive to aversive. Nature 490:402-406.

Lim MM, Liu Y, Ryabinin AE, Bai Y, Wang Z, Young LJ (2007) CRF receptors in the nucleus accumbens modulate partner preference in prairie voles. Horm Behav 51:508-515.

Liu X, Chen Y, Tong J, Reynolds AM, Proudfoot SC, Qi J, Penzes P, Lu Y, Liu QS (2016) Epac signaling is required for cocaine-induced change in AMPA receptor subunit composition in the ventral tegmental area. J Neurosci 36:4802-4815.

Merali Z, McIntosh J, Anisman H (2004) Anticipatory cues differentially provoke in vivo peptidergic and monoaminergic release at the medial prefrontal cortex. Neuropsychopharmacology 29:1409-1418.

Merchenthaler I (1984) Corticotropin releasing factor (CRF)-like immunoreactivity in the rat central nervous system: extrahypothalamic distribution. Peptides. 5:53-69.

Mineur YS, Obayemi A, Wigestrand MB, Fote GM, Calarco CA, Li AM, Picciotto MR (2013) Cholinergic signaling in the hippocampus regulates social stress resilience and anxiety- and depression-like behavior. Proc Natl Acad Sci U S A 110:3573-3578.

Oh SW, Harris JA, Ng L, Winslow B, Cain N, Mihalas S, Wang Q, Lau C, Kuan L, Henry AM, Mortrud MT, Ouellette B, Nguyen TN, Sorensen SA, Slaughterbeck CR, Wakeman W, Li Y, Feng D, Ho A, Nicholas E (2014) A mesoscale connectome of the mouse brain. Nature 508:207-214.

Ohmura Y, Yamaguchi T, Futami Y, Togashi H, Izumi T, Matsumoto M, Yoshida T, Yoshioka M (2009) Corticotropin releasing factor enhances attentional function as assessed by the five-choice serial reaction time task in rats. Behav Brain Res 198:429-433.

Okada K, Nishizawa K, Setogawa S, Hashimoto K, Kobayashi K (2018) Task-dependent function of striatal cholinergic interneurons in behavioural flexibility. Eur J Neurosci 47:1174-1183.

Peciña S, Schulkin J, Berridge KC (2006) Nucleus accumbens corticotropinreleasing factor increases cue-triggered motivation for sucrose reward: paradoxical positive incentive effects in stress? BMC Biol 4:8. 
Peng J, Long B, Yuan J, Peng X, Ni H, Li X, Gong H, Luo Q, Li A (2017) A quantitative analysis of the distribution of $\mathrm{CRH}$ neurons in whole mouse brain. Front Neuroanat 11:63.

Prado VF, Janickova H, Al-Onaizi MA, Prado MA (2017) Cholinergic circuits in cognitive flexibility. Neuroscience 345:130-141.

Ragozzino ME (2003) Acetylcholine actions in the dorsomedial striatum support the flexible shifting of response patterns. Neurobiol Learn Mem $80: 257-267$

Ragozzino ME, Mohler EG, Prior M, Palencia CA, Rozman S (2009) Acetylcholine activity in selective striatal regions supports behavioral flexibility. Neurobiol Learn Mem 91:13-22.

Riegel AC, Williams JT (2008) CRF facilitates calcium release from intracellular stores in midbrain dopamine neurons. Neuron 57:559-570.

Roscioni SS, Elzinga CR, Schmidt M (2008) Epac: effectors and biological functions. Naunyn Schmiedebergs Arch Pharmacol 377:345-357.

Sauvage M, Steckler T (2001) Detection of corticotropin-releasing hormone receptor 1 immunoreactivity in cholinergic, dopaminergic and noradrenergic neurons of the murine basal forebrain and brainstem nuclei: potential implication for arousal and attention. Neuroscience 104:643-652.

Schmidt LS, Miller AD, Lester DB, Bay-Richter C, Schülein C, FrikkeSchmidt H, Wess J, Blaha CD, Woldbye DP, Fink-Jensen A, Wortwein G (2010) Increased amphetamine-induced locomotor activity, sensitization, and accumbal dopamine release in M5 muscarinic receptor knockout mice. Psychopharmacology 207:547-558.

Shin JH, Adrover MF, Wess J, Alvarez VA (2015) Muscarinic regulation of dopamine and glutamate transmission in the nucleus accumbens. Proc Natl Acad Sci U S A 112:8124-8129.

Shin JH, Adrover MF, Alvarez VA (2017) Distinctive modulation of dopamine release in the nucleus accumbens shell mediated by dopamine and acetylcholine receptors. J Neurosci 37:11166-11180.

Smani T, Calderón-Sanchez E, Gómez-Hurtado N, Fernández-Velasco M, Cachofeiro V, Lahera V, Ordoñez A, Delgado C (2010) Mechanisms underlying the activation of L-type calcium channels by urocortin in rat ventricular myocytes. Cardiovasc Res 87:459-466.

Steckler T, Holsboer F (1999) Corticotropin-releasing hormone receptor subtypes and emotion. Biological psychiatry 46:1480-1508.

Stott JB, Barrese V, Greenwood IA (2016) Kv7 channel activation underpins EPAC-dependent relaxations of rat arteries. Arterioscler Thromb Vasc Biol 36:2404-2411.

Stouffer MA, Woods CA, Patel JC, Lee CR, Witkovsky P, Bao L, Machold RP, Jones KT, de Vaca SC, Reith ME, Carr KD, Rice ME (2015) Insulin enhances striatal dopamine release by activating cholinergic interneurons and thereby signals reward. Nat Commun 6:8543.

Tanimura A, Pancani T, Lim SAO, Tubert C, Melendez AE, Shen W, Surmeier DJ (2018) Striatal cholinergic interneurons and Parkinson's disease. Eur J Neurosci 47:1148-1158.

Tejeda HA, Wu J, Kornspun AR, Pignatelli M, Kashtelyan V, Krashes MJ, Lowell BB, Carlezon WA Jr, Bonci A (2017) Pathway- and Cell-Specific Kappa-Opioid Receptor Modulation of Excitation-Inhibition Balance Differentially Gates D1 and D2 Accumbens Neuron Activity. Neuron 93:147-163.
Threlfell S, Lalic T, Platt NJ, Jennings KA, Deisseroth K, Cragg SJ (2012) Striatal dopamine release is triggered by synchronized activity in cholinergic interneurons. Neuron 75:58-64.

Traver S, Marien M, Martin E, Hirsch EC, Michel PP (2006) The phenotypic differentiation of locus ceruleus noradrenergic neurons mediated by brain-derived neurotrophic factor is enhanced by corticotropin releasing factor through the activation of a cAMP-dependent signaling pathway. Mol Pharmacol 70:30-40.

Tubert C, Taravini IRE, Flores-Barrera E, Sánchez GM, Prost MA, Avale ME, Tseng KY, Rela L, Murer MG (2016) Decrease of a current mediated by Kv1.3 channels causes striatal cholinergic interneuron hyperexcitability in experimental parkinsonism. Cell Rep 16:2749-2762.

Valentino RJ, Van Bockstaele E, Bangasser D (2013) Sex-specific cell signaling: the corticotropin-releasing factor receptor model. Trends Pharmacol Sci 34:437-444.

Van Kolen K, Dautzenberg FM, Verstraeten K, Royaux I, De Hoogt R, Gutknecht E, Peeters PJ (2010) Corticotropin releasing factor-induced ERK phosphorylation in AtT20 cells occurs via a cAMP-dependent mechanism requiring EPAC2. Neuropharmacology 58:135-144.

Van Pett K, Viau V, Bittencourt JC, Chan RK, Li HY, Arias C, Prins GS, Perrin M, Vale W, Sawchenko PE (2000) Distribution of mRNAs encoding CRF receptors in brain and pituitary of rat and mouse. J Comp Neurol 428:191-212.

Wanat MJ, Hopf FW, Stuber GD, Phillips PE, Bonci A (2008) Corticotropin-releasing factor increases mouse ventral tegmental area dopamine neuron firing through a protein kinase $\mathrm{C}$-dependent enhancement of Ih. J Physiol 586:2157-2170.

Wang B, Shaham Y, Zitzman D, Azari S, Wise RA, You ZB (2005) Cocaine experience establishes control of midbrain glutamate and dopamine by corticotropin-releasing factor: a role in stress-induced relapse to drug seeking. J Neurosci 25:5389-5396.

Warner-Schmidt JL, Schmidt EF, Marshall JJ, Rubin AJ, Arango-Lievano M, Kaplitt MG, Ibañez-Tallon I, Heintz N, Greengard P (2012) Cholinergic interneurons in the nucleus accumbens regulate depression-like behavior. Proc Natl Acad Sci U S A 109:11360-11365.

Wonnacott S, Kaiser S, Mogg A, Soliakov L, Jones IW (2000) Presynaptic nicotinic receptors modulating dopamine release in the rat striatum. Eur J Pharmacol 393:51-58.

Yan Z, Surmeier DJ (1996) Muscarinic (m2/m4) receptors reduce N- and P-type $\mathrm{Ca}^{2+}$ currents in rat neostriatal cholinergic interneurons through a fast, membrane-delimited, G-protein pathway. J Neurosci 16:25922604.

Zhang L, Zhou FM, Dani JA (2004) Cholinergic drugs for Alzheimer's disease enhance in vitro dopamine release. Mol Pharmacol 66:538-544.

Zhang W, Yamada M, Gomeza J, Basile AS, Wess J (2002) Multiple muscarinic acetylcholine receptor subtypes modulate striatal dopamine release, as studied with M1-M5 muscarinic receptor knock-out mice. J Neurosci 22:6347-6352.

Zhou FM, Wilson CJ, Dani JA (2002) Cholinergic interneuron characteristics and nicotinic properties in the striatum. J Neurobiol 53:590605. 